\title{
Ecografia escrotal: perlas, patrones y errores
}

\author{
De Luis Pastor E*, Villanueva Marcos A*, Zudaire Díaz-Tejeiro B*, Benito Boillos A*, \\ Bondía Gracia JM*, Rincón A**, Gil Marculeta R***. \\ *Servicio de Radiología. Clinica Universitaria de Navarra. Universidad de Navarra. Pamplona. \\ **Servicio de Urología. Clínica Universitaria de Navarra. Pamplona. ***Radiología. Clínica San Miguel. Badajoz.
}

Actas Urol Esp. 2007;31(8):895-910

\section{RESUMEN}

\section{ECOGRAFÍA ESCROTAL: PERLAS, PATRONES Y ERRORES}

En este trabajo presentamos una revisión de los hallazgos de la ecografía escrotal mostrando variantes anatómicas escrotales (dilatación de la rete testis, apéndices testiculares y epididimarios) que simulan enfermedad. Revisamos la patología escrotal agrupada semiológicamente incluyendo lesiones con calcio (escrotolitos, calcificación de la albugínea, microlitiasis testicular, calcificaciones epididimarias, neoplasias testiculares con calcificaciones), lesiones con contenido líquido (quistes de epidídimo, de la albugínea, testiculares, varicocele intratesticular, abscesos y hematomas testiculares, varicocele extratesticular con contenido ecogénico), lesiones nodulares sólidas de testículo (infartos y neoplasias) y lesiones difusas del testículo (linfoma, leucemia, hiperplasia linfoide, orquitis). Otra de las utilidades de la ecografia escrotal es considerar determinados hallazgos escrotales como marcadores de patología extraescrotal. Mostramos la asociación de neoplasias extraescrotales con varicocele derecho y varios casos de "Burn-out tumor" con neoplasia testicular "in situ" y sus hallazgos de RM, TC y PET.

Se concluye que el conocimiento de la anatomía normal ecográfica, de los diferentes patrones de presentación de las lesiones y de los hallazgos escrotales que indican patología extratesticular ayudan en el manejo de los pacientes y pueden evitar cirugias innecesarias.

Palabras clave: Lesiones escrotales. Ecografia. "Burn out”. Tumores testículo.

\section{ABSTRACT}

\section{SCROTAL ULTRASOUND: PEARLS, PATTERNS AND PITFALLS}

We present a review of the scrotal ultrasound findings showing normal anatomic variants that may simulate scrotal pathology (rete testis dilatation, normal testicle and epididymis appendages). US patterns of the scrotal pathology may be classified as: calcified (scrotal and albuginea calcifications, microcalcifications, epididymis calcifications, testicular tumors with calcium), cystic appereance (intratesticular and echogenic varicocele, epididymis cysts, albuginea cysts, haematoma, abscess), solid nodular testicular lesions (infarct, neoplasm) and diffuse lesions (orchitis, lymphoid hyperplasia lymphoma, leukemia). Testicular ultrasound may be helpful in detecting extraescrotal pathologies. There is a known relationship between right varicocele and extratesticular neoplasms. We also show some cases of Burn-out testicular tumor and their MR, CT and PET findings.

The knowledge of normal US scrotal anatomy, US patterns of the scrotal lesions and scrotal findings that suggest extratesticular pathologies are crucial in the management of testicular pathology and if unnecessary orchiectomies want to be avoided.

Keywords: Scrotal lesions. Ultrasound. Burn out tumor. Testicular neoplasm. 
$\mathrm{L}$ a ecografía con un transductor de alta frecuencia es la técnica de imagen de elección para el diagnóstico de la patología escrotal. Permite identificar estructuras y lesiones de pequeño tamaño en el escroto (Fig. 1). Tiene una sensibilidad próxima al 100\% para el diagnóstico de masas escrotales. La principal razón para el estudio ecográfico de un paciente con una masa en el escroto es determinar si se trata de un tumor testicular. Las neoplasias de testículo son las más frecuentes en pacientes jóvenes. La mayoría de las lesiones escrotales son extratesticulares y más del 95\% de las lesiones intratesticulares son malignas. Sin embargo, los hallazgos de la ecografía escrotal se asocian con frecuencia a falsos positivos de neoplasia testicular maligna que requieren habitualmente orquiectomía ${ }^{1}$. Es preciso que el especialista conozca las variantes anatómicas normales que simulan enfermedad y disponer de un esquema mental que permita manejar adecuadamente los hallazgos ecográficos e indicar con precisión la necesidad de estudio histológico.

La ecografía juega también un importante papel en la patología aguda del escroto que puede ocasionar daño irreversible testicular y en la detección de microlitiasis testicular que cursa con mayor incidencia de neoplasias en el testículo. Por otro lado, pensar en una neoplasia testicular en pacientes jóvenes puede ser el camino para encontrar la explicación de adenopatías,

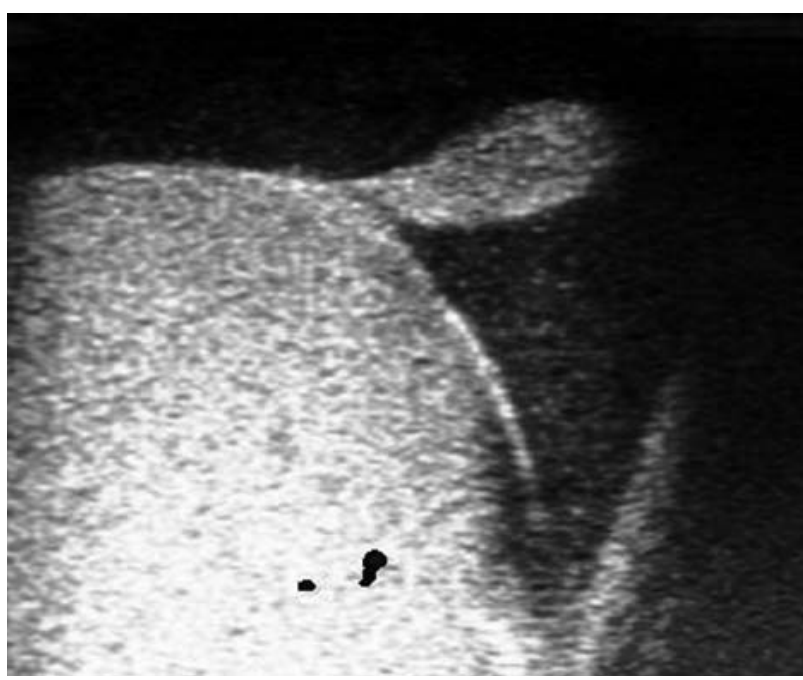

FIGURA 1. Apéndice testicular normal en un adulto (2 $x$ $6 \mathrm{~mm}$ ) con hidrocele. metástasis torácicas o abdominales de origen hasta entonces desconocido. En sentido inverso, determinados hallazgos ecográficos observados en el escroto deben llevar al radiólogo a buscar patología extraescrotal. Así ocurre en el varicocele derecho y en los llamados "Burn out tumor", casos de tumor testicular intratubular con diseminación a distancia.

En cualquier caso, una valoración correcta de la patología escrotal comprende un estudio clinico adecuado. De manera orientativa las lesiones con un tamaño mayor de $1 \mathrm{~cm}$. en ecografía y palpables suelen ser malignas. Las lesiones con un tamaño mayor de $1 \mathrm{~cm}$. en ecografía y no palpables suelen ser benignas. La mayoría de las lesiones menores de $1 \mathrm{~cm}$ no son palpables. En este grupo tiene interés el conocimiento de patrones que pueden ayudar a evitar errores diagnósticos. Nosotros hemos considerado cuatro tipos de patrones: lesiones con calcio, lesiones con contenido líquido, lesiones nodulares sólidas de testículo y lesiones difusas de testículo.

Disponemos de un método sensible para una patología importante y cuyos hallazgos podemos comprender de una manera esquematizada.

\section{Testiculo normal}

Es útil conocer las características ecográficas del testículo normal para entender el origen y la localización de las lesiones testiculares y para identificar las variantes anatómicas que simulan enfermedad en la ecografia. En el adulto tiene un aspecto hipoecoico homogéneo, con forma ovoidea y un tamaño de $3 \times 2 \times 5 \mathrm{~cm}$ (Fig. 2).

Está recubierto por dos capas, una más interna, la túnica albugínea de tipo fibroso adherida al testículo y una más externa, la túnica vaginalis una serosa con dos capas, visceral y parietal. En la ecografía son indistinguibles. La albugínea, la capa fibrosa, penetra a través de uno de los polos del testículo conformando un septo incompleto llamado mediastino. En su interior hay vasos que se detectan mediante ecografía en el 50\% de los casos (Fig. 3). Otros pequeños septos parten desde la albugínea hacia el centro dividiendo el testículo en lóbulos. En su interior se encuentran los túbulos seminíferos que drenan a través de los túbulos rectos a unas espacios dilatados situados en el interior del medias- 


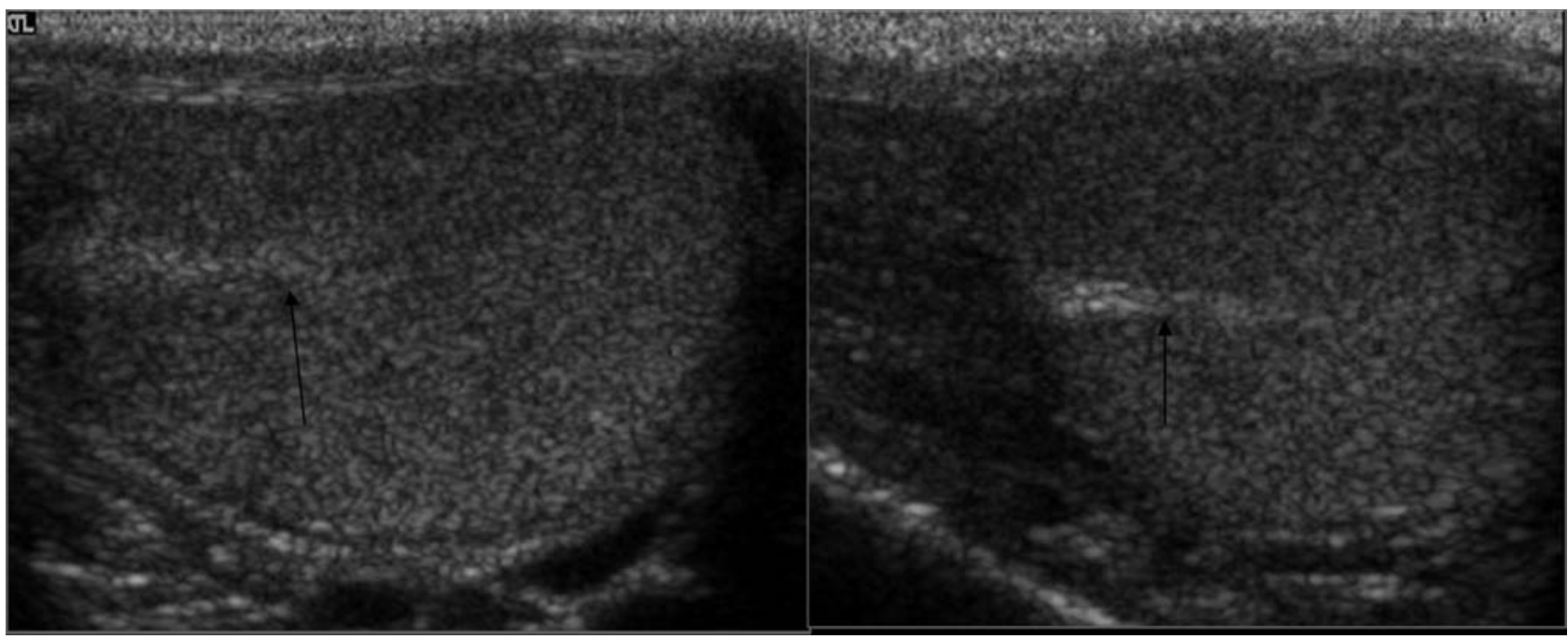

FIGURA 2. Testiculos normales: Dos cortes oblicuos muestran ecogenicidad homogénea y forma elipsoide. El mediastino (flecha negra) aparece como una banda ecogénica. En él desembocan los túbulos seminíferos que forman la rete testis situada en su interior $y$ vasos, no apreciables.

tino llamados rete testis ${ }^{2,3}$. Habitualmente no se identifica esta estructura mediante ecografía salvo cuando la dilatación es acusada y produce un aspecto quístico del mediastino (Fig. 3). La dilatación de la rete testis no es palpable y puede llegar a medir hasta $4 \mathrm{~cm}$. Suele ser bilateral y asimétrica y con mucha frecuencia se asocia a quistes de epidídimo ${ }^{3}$.

A partir del polo superior del testículo y de la cabeza del epidídimo se originan unas prolongaciones digitiformes llamadas apéndices del testículo y epidídimo. Son remanentes embrionarios de los conductos mesonéfrico y paramesonéfrico. Estos apéndices pueden torsionarse siendo ésta una de las causas de patología escrotal aguda en niños. La identificación de un apéndice testicular mayor de 5-6 mm. en un niño con escroto agudo es sugestivo de torsión apendicular. En el adulto esta medida corresponde a un apéndice normal. Se describen cinco apéndices diferentes en el testículo y epidídimo, alguno con aspecto quístico ${ }^{4-7}$ (Fig. 4).

\section{Lesiones con calcio}

Placas de la albugínea.

Son engrosamientos focales de tipo fibroso que afectan a la túnica vaginalis y a la albuginea. Son secundarios a un traumatismo o infección ${ }^{8}$.

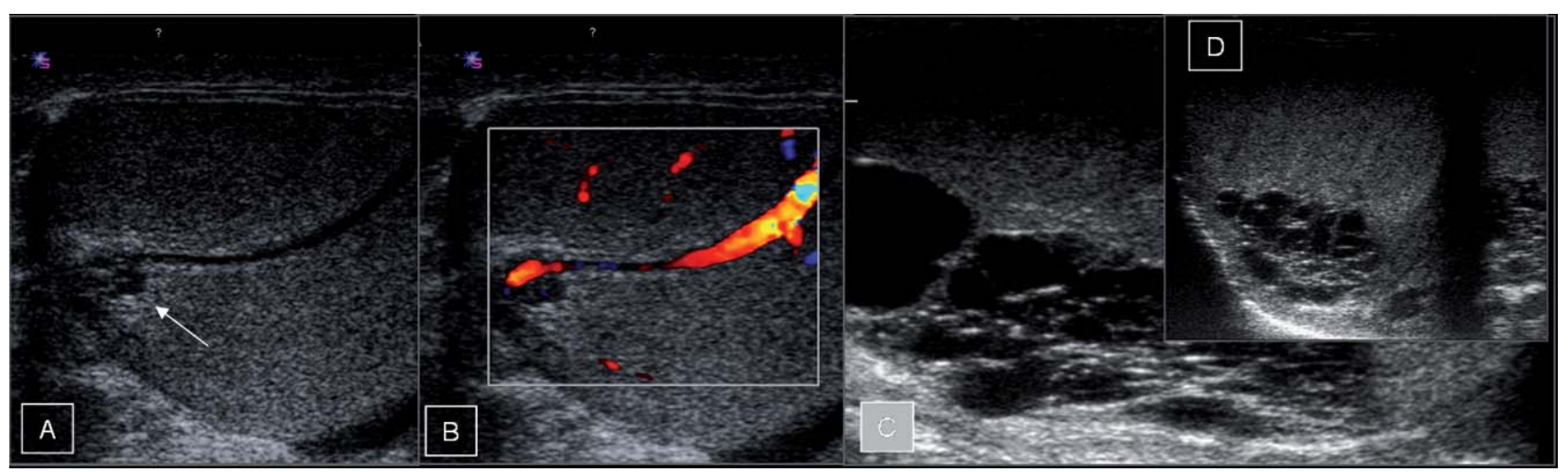

FIGURA 3. A y B Mediastino con vaso demostrado en Doppler color. Pequeña formación quística en relación con el mediastino (flecha en A), sin señal Doppler, correspondiente a una dilatación focal de la rete testis. C. Múltiples imágenes quisticas y tubulares que substituyen el mediastino y corresponden a otro paciente con dilatación la rete testis bilateral y asimétrica (flechas en $D$ ). No debe confundirse con una masa. No requiere seguimiento. 


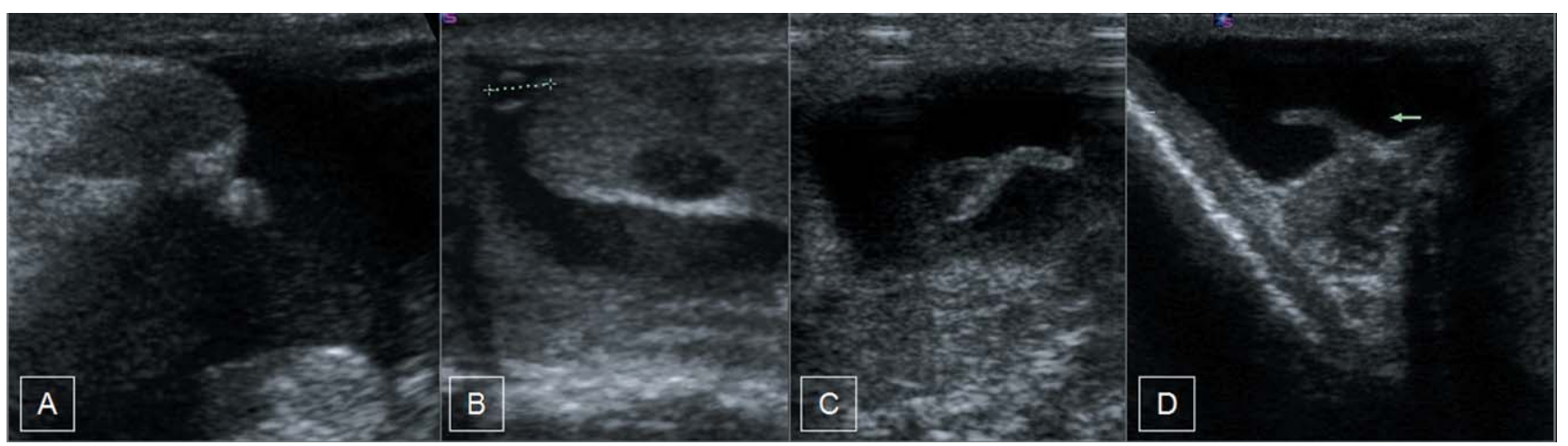

FIGURA 4. Apéndices de epididimo (A flecha y B marcadores) y testiculares (C flecha blanca y $D$ flecha verde), normales $(8$ a $10 \mathrm{~mm}$ ) en 4 pacientes adultos. Nótese el aspecto quistico de B correspondiente a una hidátide de Morgagni normal.

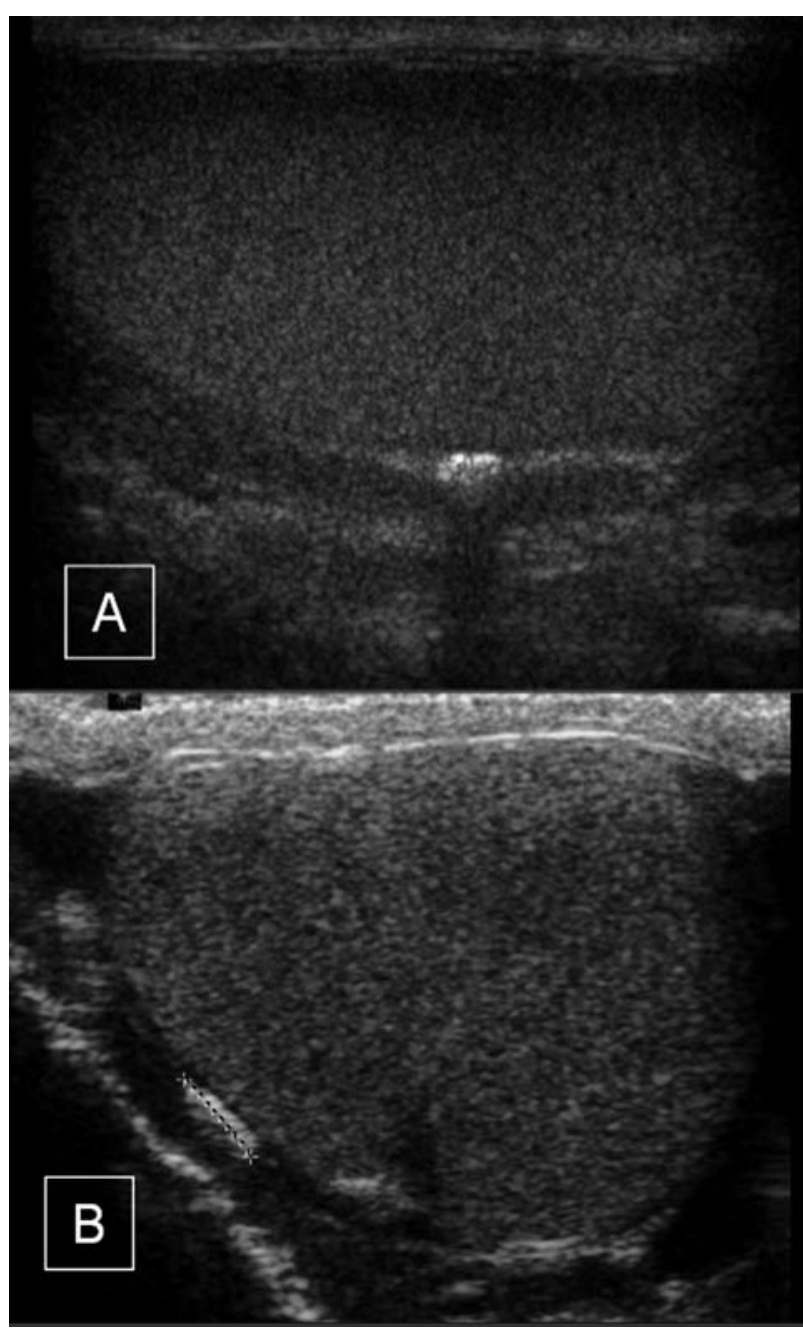

FIGURA 5. Dos casos de placas calcificadas en la albuginea.

Se palpan muy bien. En ecografia se manifiestan como imágenes lineales periféricas ecogénicas, fuera del testículo, fijas. Su identificación ecográfica resulta muy fácil si están calcificadas, lo que ocurre en el 50\% de los $\operatorname{casos}^{9}$ (Fig. 5) o cuando su tamaño es grande. En caso contrario, puede ser dificultosa, a pesar de su palpación evidente para el urólogo. Adoptan forma lisa, de placa o bien nodular. Recibe varios nombres (periorquitis crónica, proliferación fibrosa, fibroma, fibrosis paratesticular inespecífica, periorquitis granulomatosa, pseudotumor fibroso nodular, pseudotumor inflamatorio, periorquitis reactiva). En los casos de ausencia de calcificación y aspecto nodular pueden simular tumores ${ }^{10}$.

\section{Escrotolitos}

Son calcificaciones móviles en el escroto que podrían corresponder a apéndices testiculares o epididimarios torsionados ${ }^{5,9}$ (Fig. 6). También se llaman cálculos o perlas escrotales. Pueden alcanzar hasta $1 \mathrm{~cm}$ de diámetro y asociarse a hidrocele. Están formados por un depósito fibrinoide alrededor de un núcleo de hidroxiapatita lo que explica su semiología ecográfica ${ }^{11,12}$.

\section{Calcificaciones en el epidídimo}

Aisladas o múltiples, se asocian a antecedentes de epididimitis (Fig. 7). Al identificar calcificaciones en el epidídimo se debe valorar antecedentes personales de enfermedad granulomatosa, como la tuberculosis o la brucelosis, y de hematomas en el epídidimo generalmente postraumáticos ${ }^{12-14}$.

\section{Microlitiasis testicular (MT)}

Consiste en depósitos en la luz de los túbulos seminíferos, que se traducen en puntos hiperecoicos de 1 a $3 \mathrm{~mm}$ sin sombra posterior en la ecografia (Fig. 8). Se establece como criterio iden- 


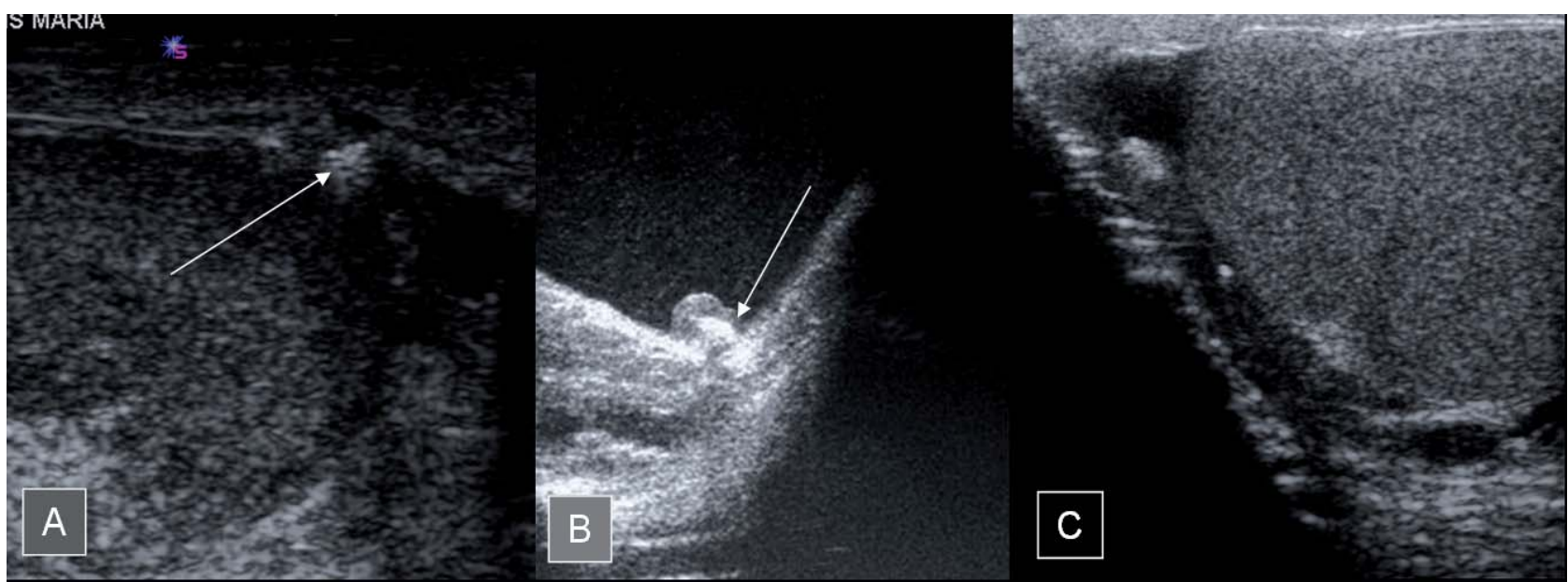

FIGURA 6. Tres casos de escrotolitos, más fáciles de identificar con hidrocele (flecha en B) que sin él (flechas en A y C) en pacientes asintomáticos. En el B se observa material ecogénico, probablemente no calcificado y sombra posterior como en A.

tificar 5 o más lesiones en un plano de corte ecográfico. Su causa no es conocida. Se produce por degeneración del epitelio de los túbulos seminíferos. Ésto da lugar a acúmulos de glicoproteinas y capas de calcio que explican la semiología ecográfica. Se diagnostica entre el 0,2 y $9 \%$ de las ecografias testiculares. Se ha descrito la coexistencia de MT con muchas enfermedades benignas o malignas como criptorquidia, hipogonadismo, infarto, microlitiasis alveolar, varicocele, torsión testicular, seudohermafroditismo masculino, síndrome de Klinefelter, SIDA, carcinoma in situ, neurofibromatosis tipo I y tumores de células germinales. En ningún caso se ha podido establecer una relación causa efecto. La concomitancia de MT y de neoplasia intra o extratesticular es espe- cialmente llamativa. Se da con una frecuencia que oscila entre el 6 y el 45\%. Ésto hace pensar que la coexistencia de MT y neoplasia no es una coincidencia. Por lo tanto en los pacientes con MT debe prestarse atención a en descartar lesiones testiculares focales mediante ecografia ${ }^{8,15,16}$.

El seguimiento de los pacientes con MT depende de la existencia o no de neoplasia testicular. Se recomienda autopalpación y exploración física anual a los pacientes que presentan MT. Se pone en duda actualmente la eficacia del seguimiento mediante ecografia anual de los pacientes con microlitiasis testicular en ausencia de antecedentes de neoplasia $8,15,16$. En un paciente con neoplasia testicular unilateral y microlitiasis contralateral debe biopsiarse este testículo porque la

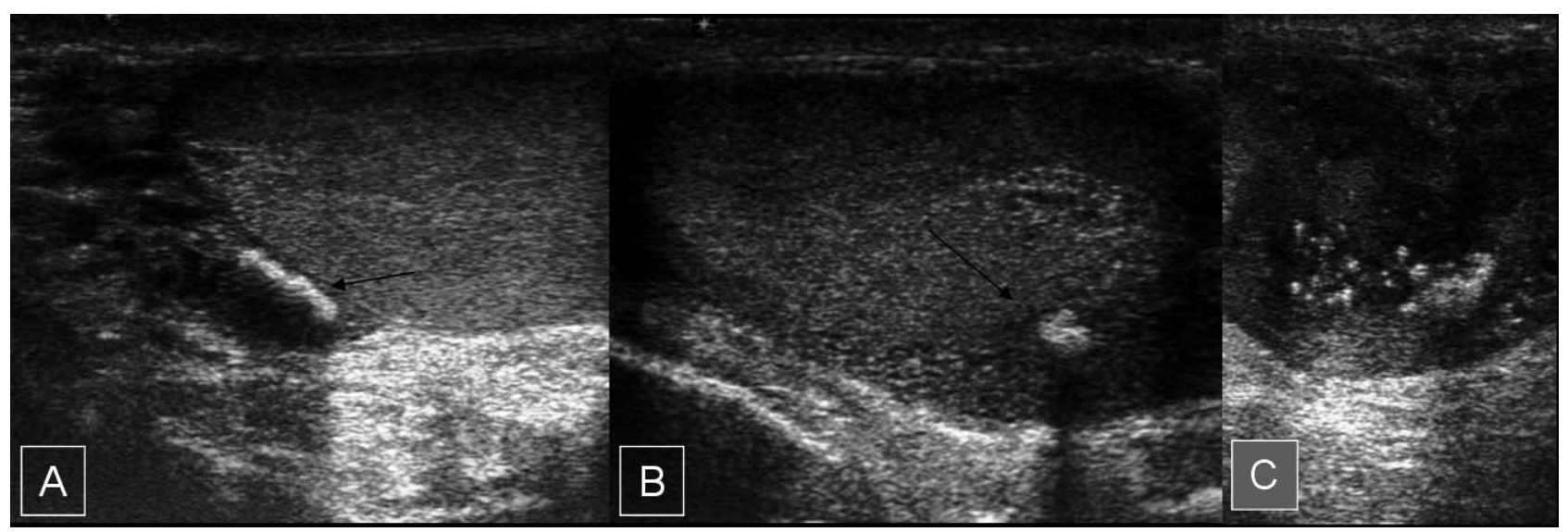

FIGURA 7. Calcificaciones en el epididimo. Única, en el cuerpo del epididimo, en un paciente sin clínica previa conocida de tipo inflamatorio (flechas en $\mathrm{A}$ y B). Ligero aumento de tamaño con áreas quísticas y múltiples calcificaciones (C) en otro paciente con clinica de epididimitis repetidas. 


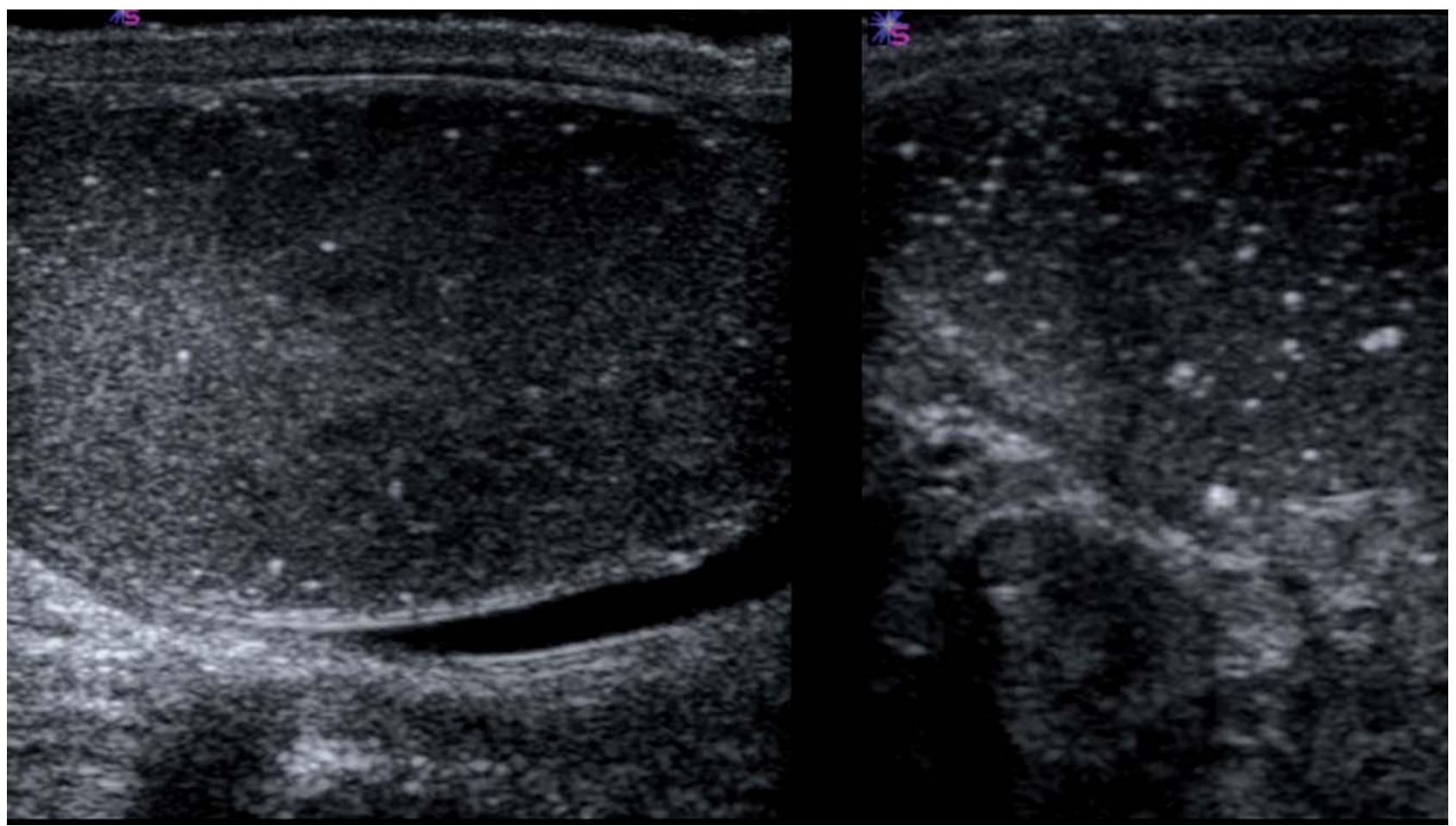

FIGURA 8. Microlitiasis. Múltiples (incontables, más de 5) imágenes puntiformes ecogénicas en ambos testículos.

incidencia de neoplasia intratubular de células germinales es muy alta. La neoplasia intratubular es el equivalente al carcinoma "in situ" testicular. Si no se demuestra neoplasia, en este grupo de pacientes con microlitiasis si está indicado el control ecográfico evolutivo. A los 5 años el 50\% de los pacientes con neoplasia intratubular desarrollan un tumor de células germinales.

\section{Quiste epidermoide}

Son lesiones benignas infrecuentes, derivadas del ectodermo. Suponen entre 1 y $2 \%$ de las masas testiculares resecadas. La imagen ecográfica se describió como patognomónica pero puede presentarse un aspecto parecido en los teratomas. Consiste en nódulos hipoecoicos con un anillo ecogénico o varios, en "capas de cebolla" (Fig. 9).

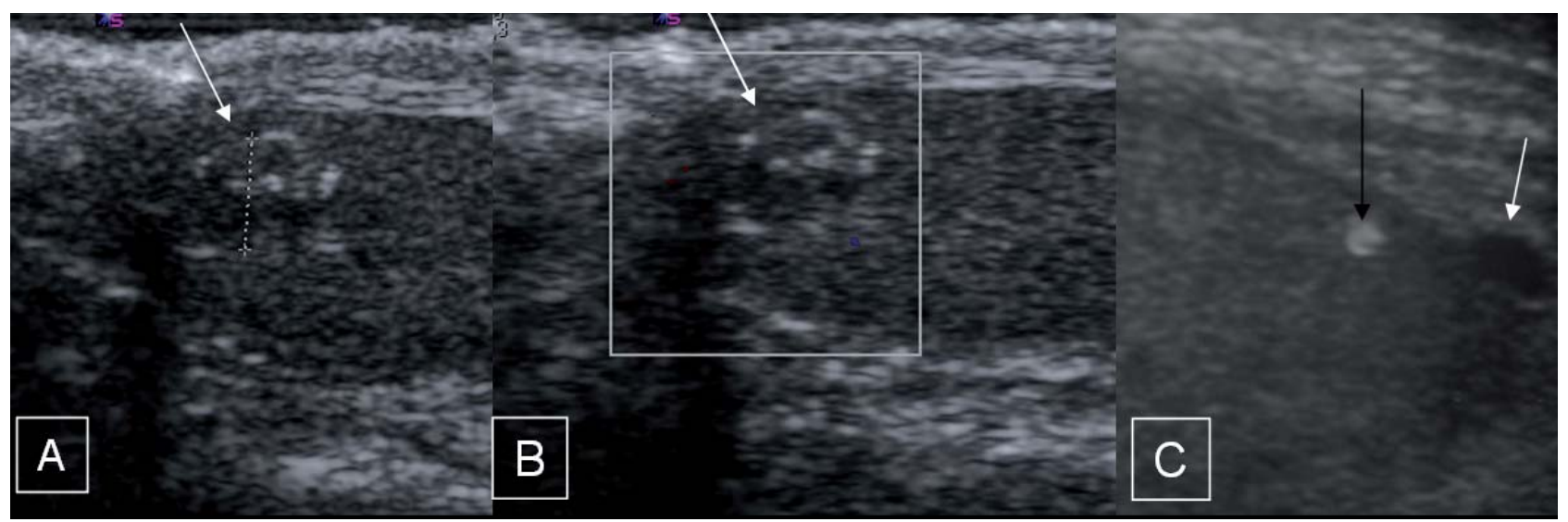

FIGURA 9. Quiste epidermoide. Paciente de 3 años con imagen redonda hipoecoica con anillo ecogénico concéntrico (flechas en $A$ y B) sin cambios en dos años compatible con quiste epidermoide. Quiste periférico inespecífico en otro paciente (C), similar a un quiste de la albuginea. En la orquiectomía llevada a cabo por sospecha de carcinoma tubular (calcificación, flecha negra en C) en el contexto de un burned out tumor se confirmó este y se comprobó que el quiste periférico (flecha blanca en C) correspondia a un quiste epidermoide (mismo caso de la figura 29). 
Es aconsejable seguimiento ecográfico. Pueden resecarse de manera parcial mediante enucleación, sin necesidad de orquiectomía, de ahí la importancia del diagnóstico ecográfico ${ }^{17,18}$.

\section{Neoplasias testiculares}

La mayoría tumores testiculares pueden presentarse como nódulos con calcificaciones por lo que su identificación no es útil en el diagnóstico diferencial (Fig. 10). Los casos de Burn out tumor que se comentan más adelante con detenimiento suelen presentar calcificaciones testiculares no asociadas a nódulo (Figs. 28 a 30)

\section{Lesiones con contenido liquido}

Las colecciones escrotales extratesticulares (hidrocele, hematocele y piocele) producen aumento de tamaño del escroto (Fig. 11). Su identificación es sencilla mediante ecografía $y$ permite descartar masas testiculares que es el principal objetivo de la ecografía escrotal. En ocasiones el aumento de tamaño del escroto está producido por contenido sólido como ocurre en las hernias. La identificación de estructuras intestinales y la maniobra de Valsalva permiten el diagnóstico (Fig. 12).

\section{Varicocele}

Son venas peritesticulares dilatadas más de 2 mm o con reflujo persistente más de 1 segundo en la maniobra de Valsalva. La mayoría de los varicoceles (85\%) se dan en la izquierda. Ésto ocurre porque el drenaje de la vena espermática izquierda a la vena renal izquierda está dificulta-

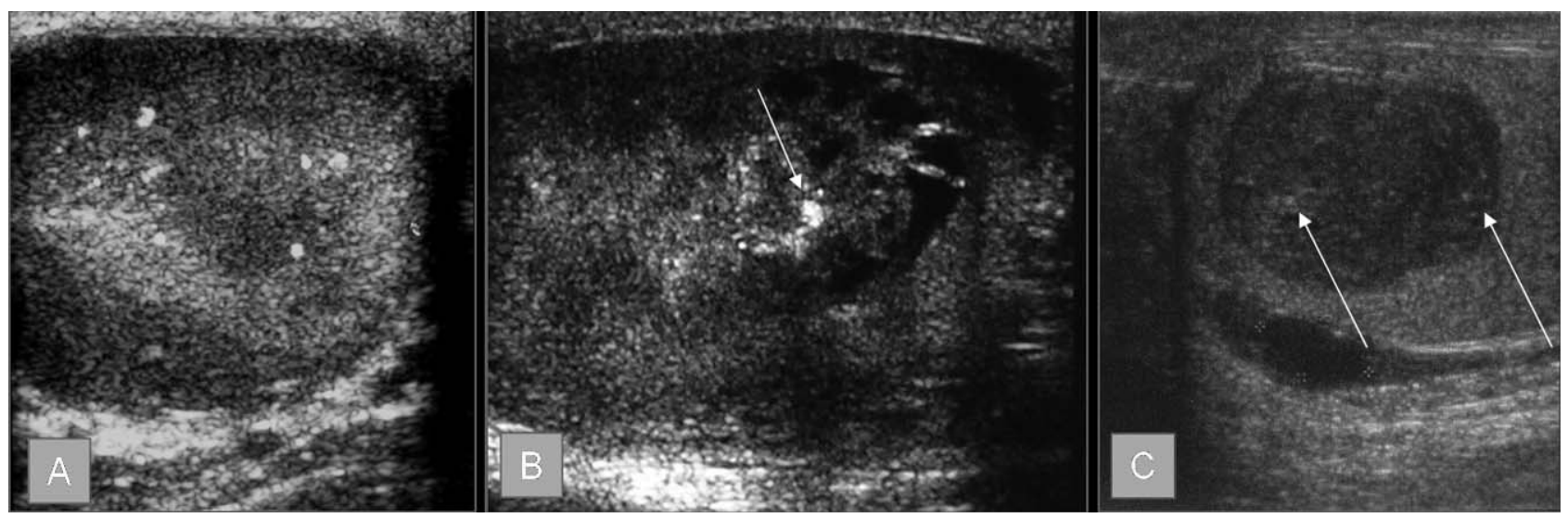

FIGURA 10. Tres casos de neoplasias testiculares con calcificaciones (flechas) de diferentes tamaños: Seminoma clasico (A), germinal mixto (B) y tumor de células de Leydig (C).

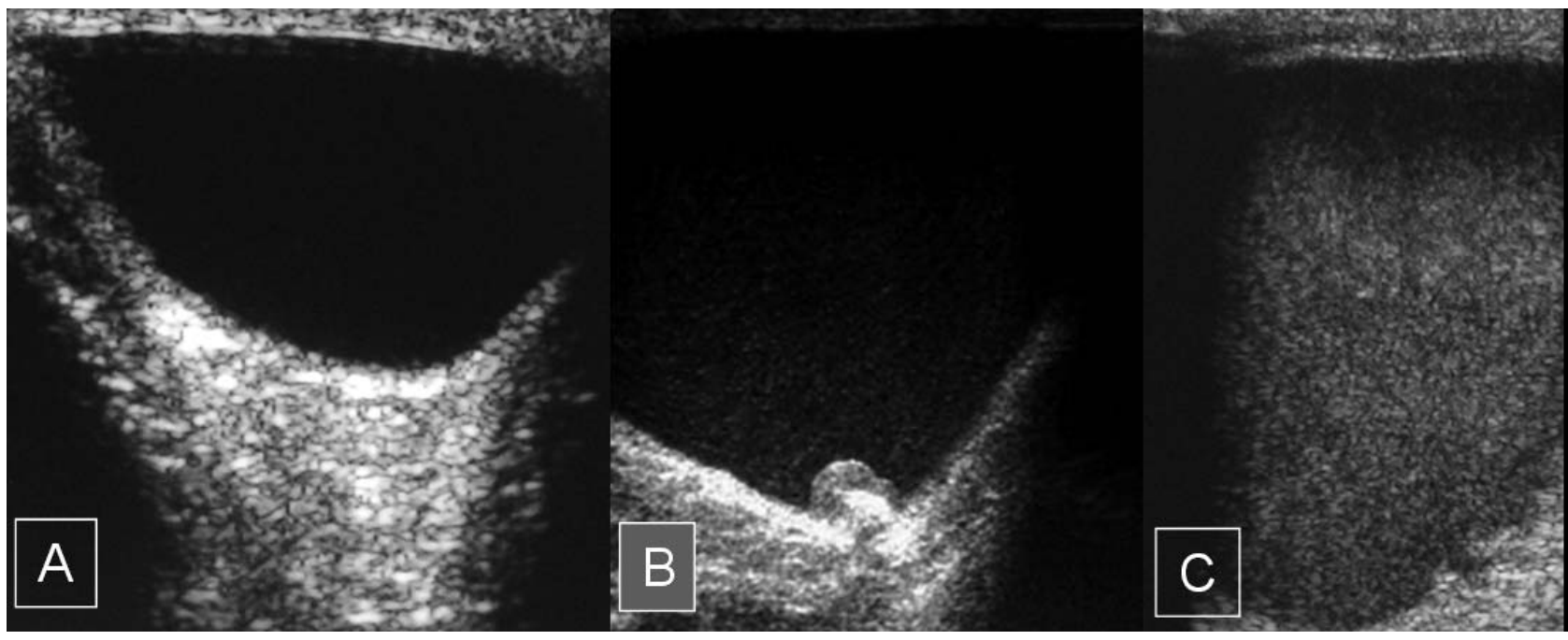

FIGURA 11. Dos casos de hidrocele, uno anecoico (A), otro ligeramente ecogénico (B) y uno de hematoma escrotal (C). 


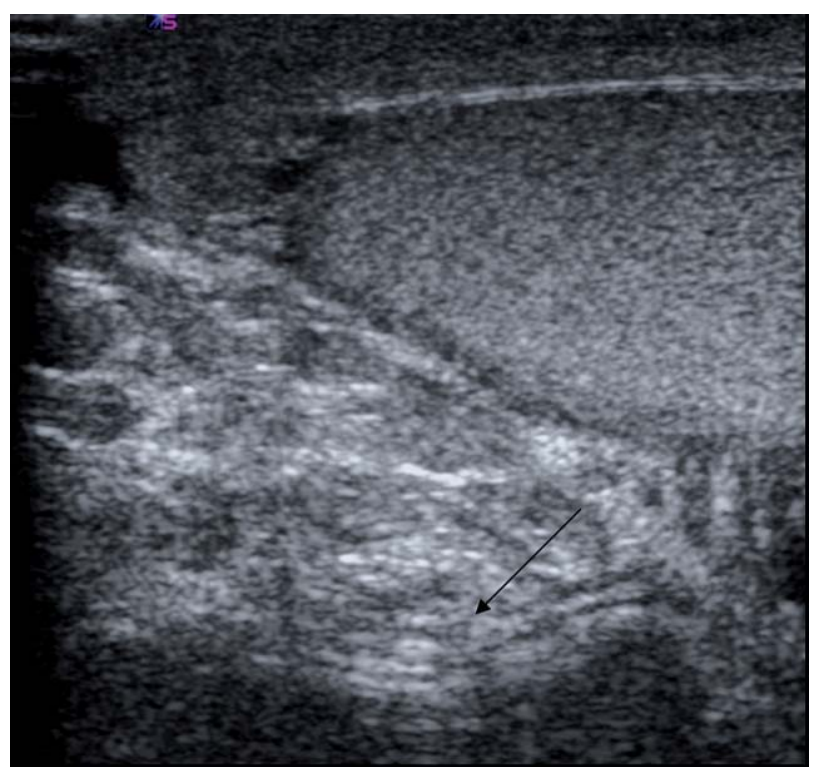

FIGURA 12. Hernia escrotal con contenido ecogénico (grasa) y estructuras intestinales (flechas).

do por la compresión que sobre ella efectúa la arteria mesentérica superior. Se identifican en ecografía como tubos con un trayecto tortuoso de aspecto hipoecoicos o, en ocasiones, ecogénicos
(Fig. 13). Algo menos del 15\% son bilaterales (Fig. 14). Los varicoceles derechos son extremadamente infrecuentes y deben hacer sospechar patología que produzca obstrucción al drenaje venoso o situs inversus.

Una forma infrecuente es el varicocele intratesticular, que suele ser unilateral. Con frecuencia se asociar a varicocele extratesticular (Fig. 15) y en ocasiones a atrofia testicular. Como el varicocele extratesticular es más frecuente en el lado izquierdo ${ }^{19,} 20$.

\section{Quistes de epidídimo y espermatoceles}

El espermatocele es la lesión escrotal más frecuente. Se observa en el $70 \%$ de las ecografias. Los quistes están rellenos de líquido seroso y pueden asentar en cualquier porción del epidídimo. Los espermatoceles están rellenos de líquido y espermatozoides. Éstos son anecoicos o con algunos ecos en su interior (Figs. 16 y 17) y se localizan en la cabeza del epidídimo. Cuando son anecoicos son indistinguibles de los quistes. Cuando su presentación es típica no requieren seguimiento ${ }^{13}$.

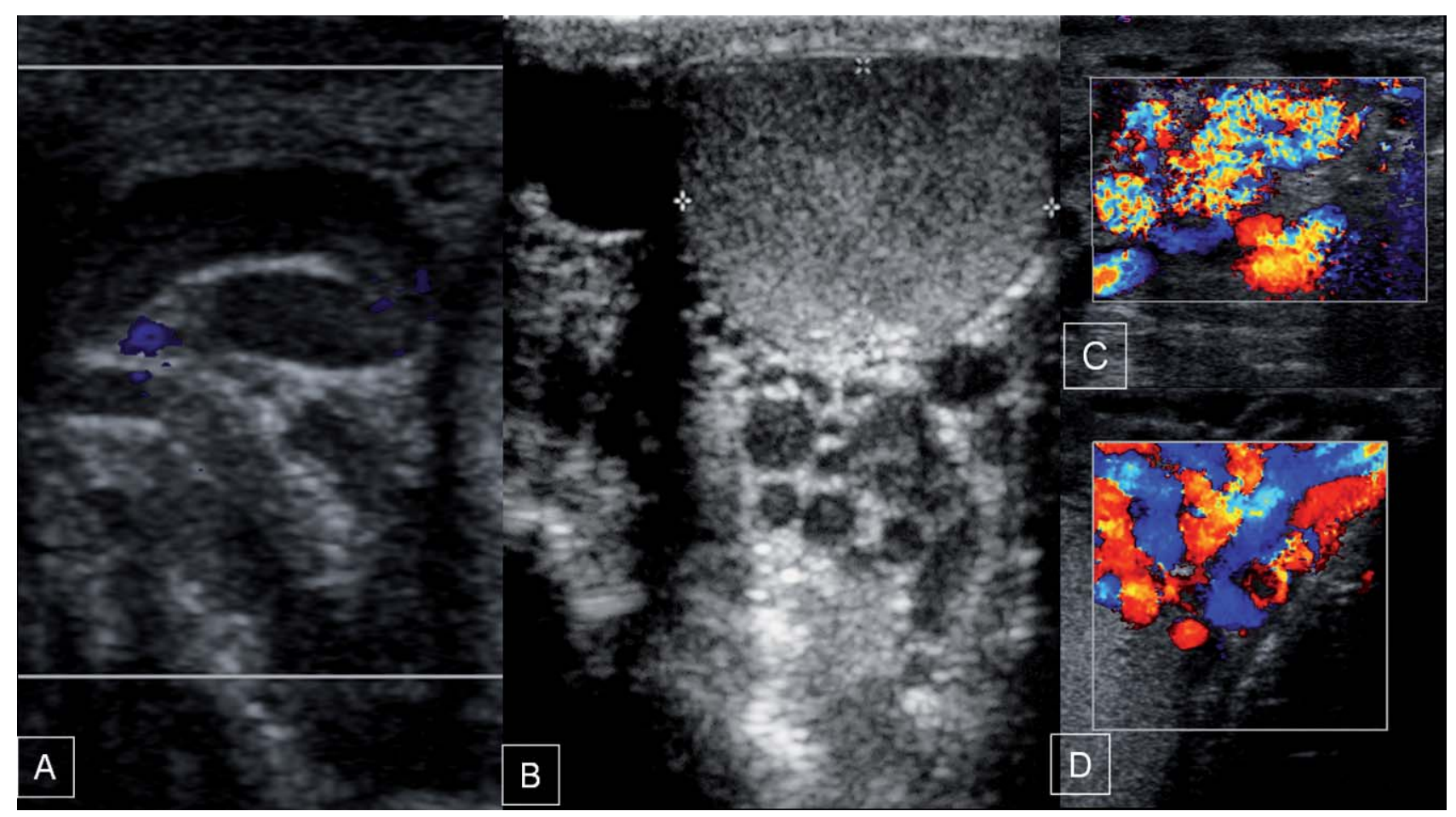

FIGURA 13. Varicocele izquierdo. Cuatro casos. ( $\mathrm{A}$ y B) tubos tortuosos (venas peritesticulares) con calibre mayor de 2 mm de aspecto ecogénico. En A se observaba el movimiento sanguíneo en ecografía convencional aunque no mediante doppler en reposo. Al efectuar la maniobra de Valsalva $(C, D)$ se observa flujo venoso mantenido más de 1 segundo. 


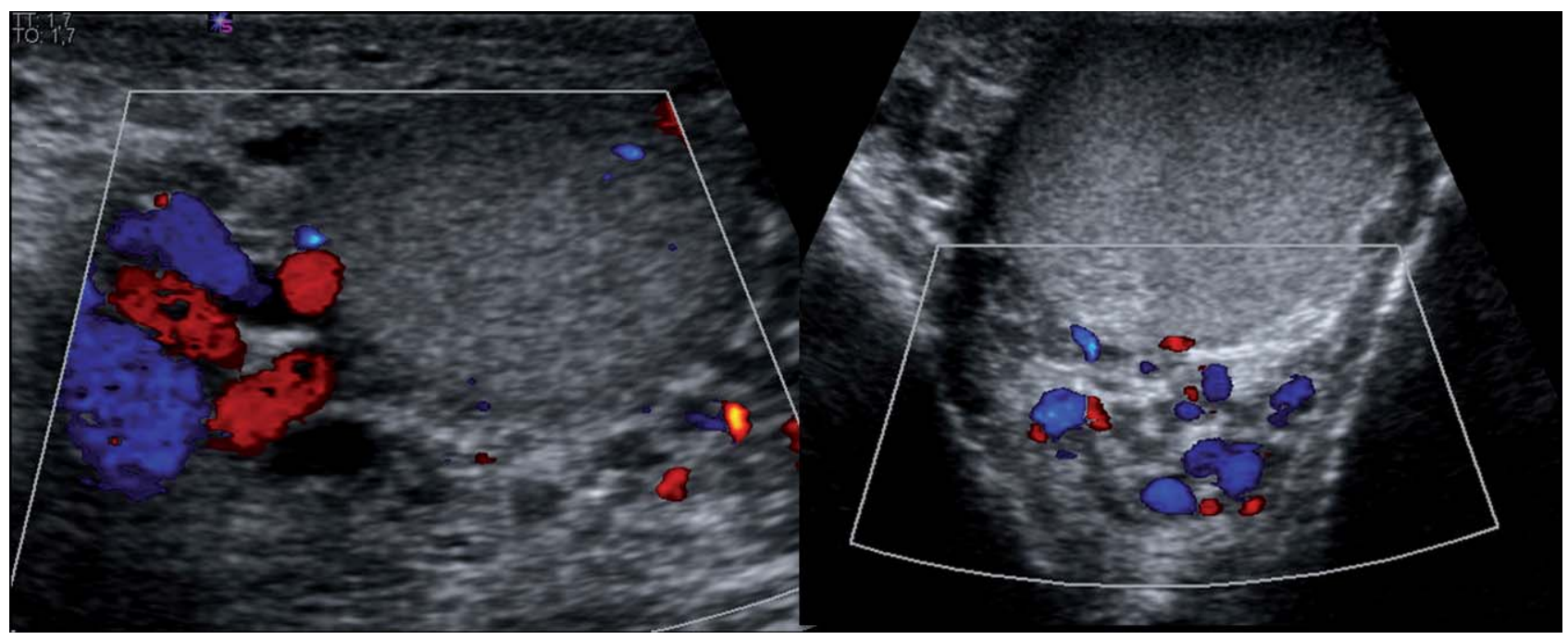

FIGURA 14. Varicocele bilateral sin adenopatias retroperitoneales

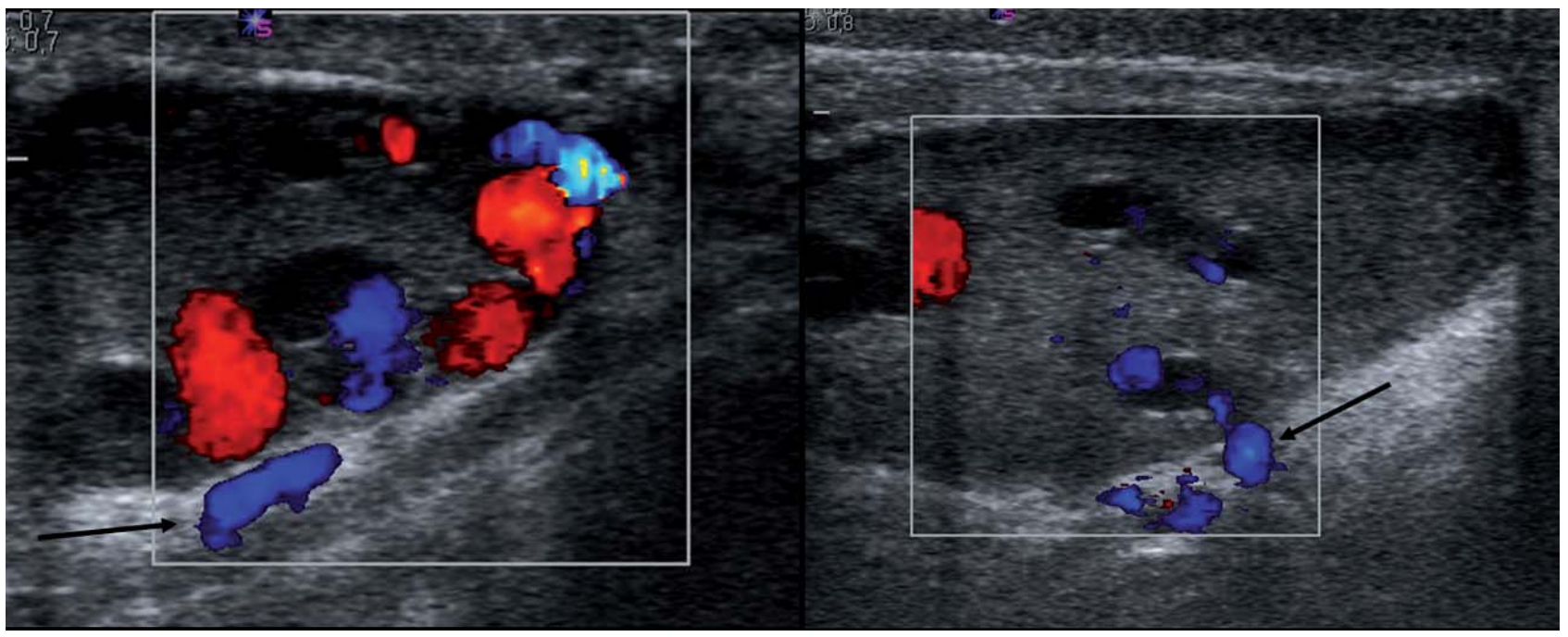

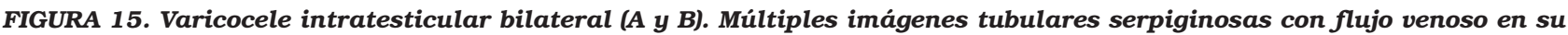
interior de predominio subcapsular, con varicocele extratesticular (flechas).

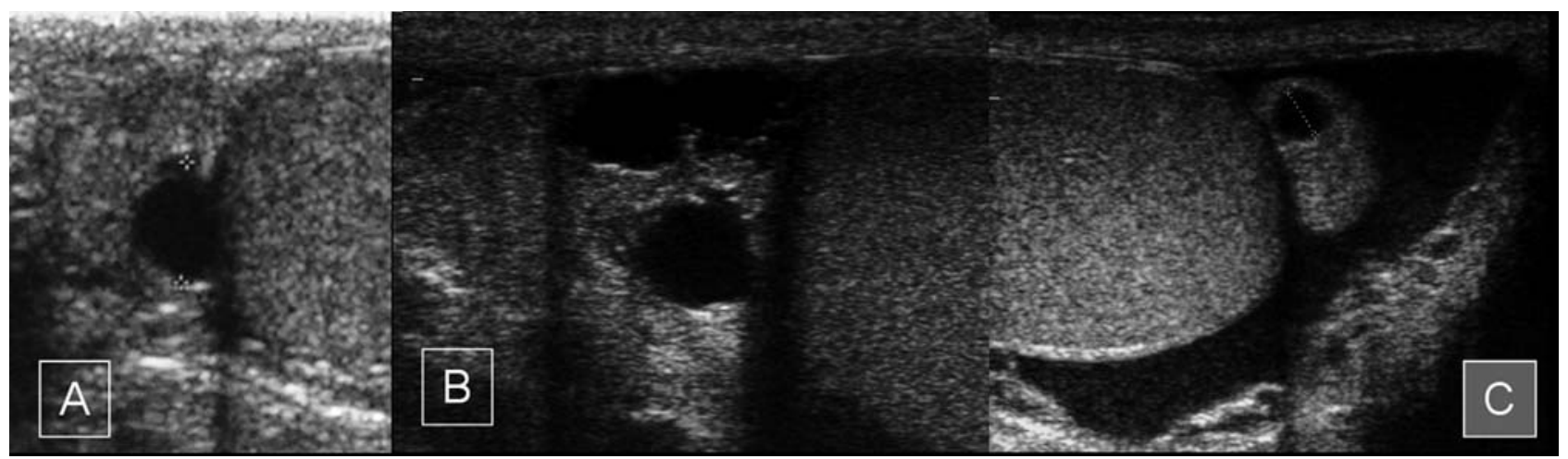

FIGURA 16. Quiste de epididimo: presentación típica. Tres casos anecoicos con refuerzo posterior y están en la cabeza del epididimo. Sin comprobación histológica. 


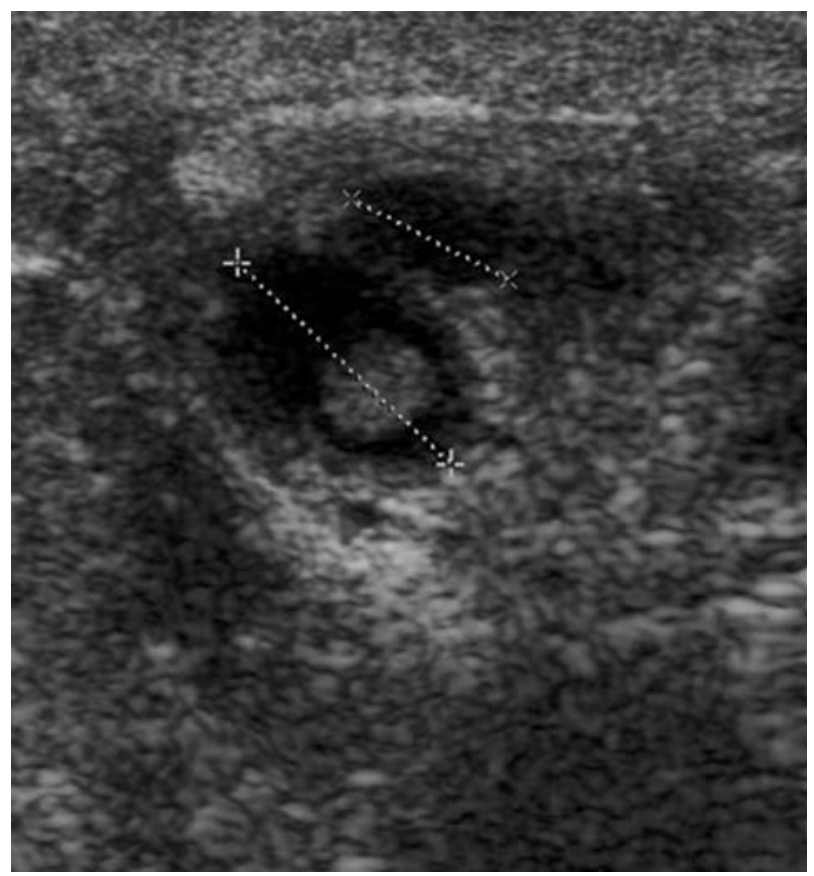

FIGURA 17. Guistes de epididimo y espermatocele: presentación atípica. Tres casos, uno de quiste (A, flecha), demostrado en anatomía patológica (orquiectomía por neoplasia testicular) no presenta refuerzo. La histologia demostró en este caso "Dilatación quística de uno de los conductos epididimarios con material de secreción y sangre entremezclados en su luz". En el segundo caso B y C se observa disminución de tamaño y aparición de material ecogénico (flecha en C) en un plazo de 3 años en un probable espermatocele (C). El tercer caso (D) aparece un quiste ecogénico por incorrecta distancia focal o aumento relativo de la ganancia (flecha en D). B,C y D sin comprobación histológica.

Quistes de la albugínea

Su palpación es dura y fácil de reconocer. A pesar de ello, si cumplen criterios ecográficos de quiste simple no deben ser tenidos en cuenta. Son solitarios, muy periféricos y pequeños.

Quistes testiculares

Los quistes testiculares son mucho menos frecuentes (10\%) que los de epididimo. No modifican su aspecto a lo largo del tiempo. Se trata de quistes simples que no son palpables, incluso con tamaños de hasta $3 \mathrm{~cm}$. La mayor incidencia tiene lugar en adultos. Pueden ser únicos o múltiples y asociarse a quistes o espermatoceles de epidídimo. No requieren tratamiento ${ }^{3,21}$ (Fig. 18).

\section{Hematomas testiculares}

Tienen un aspecto hipoecoico o heterogéneo (Fig. 19). Son consecuencia de traumatismos en

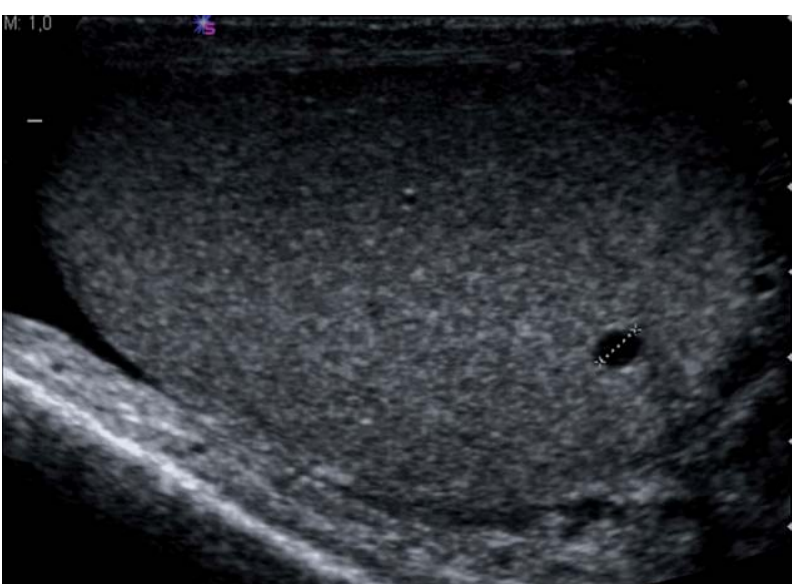

FIGURA 18. Quiste de testiculo: quiste simple (redondo anecoico con refuerzo posterior) de $3 \mathrm{~mm}$ en el interior del testiculo.

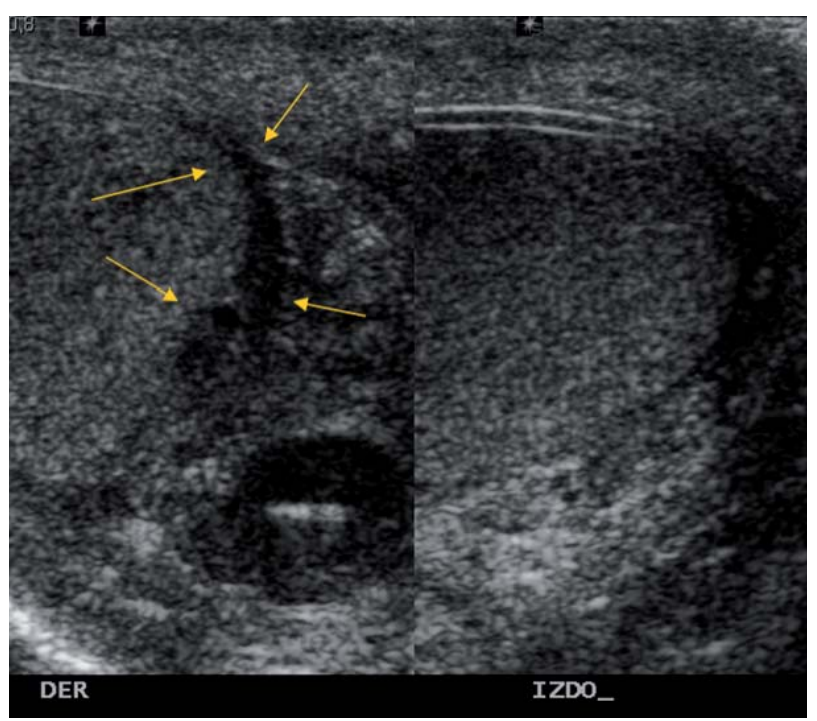

FIGURA 19. Traumatismo testicular (atrapamiento en sedestación): Hematoma testicular derecho subcapsular (flechas).

los que es importante tratar de identificar si existe integridad de la albuginea, criterio de tratamiento conservador.

\section{Lesiones nodulares sólidas de testículo}

Neoplasias testiculares

El cáncer de testículo supone el $1 \%$ de las neoplasias en los hombres. Sin embargo en el grupo de edad entre los varones de 20 a 35 años es la neoplasia más frecuente. Las neoplasias testiculares se clasifican en primarios de estirpe germinal, primarios no germinales y metástasis. Los 
tumores de células germinales constituyen el 95\% de los tumores de testículo. De ellos entre el 40 y $50 \%$ son seminomas y el $40 \%$ son tumores germinales mixtos. Entre los no germinales los derivados de las células de Leydig son los más frecuentes. Su manera de presentación habitual es como nódulo sólido complejo. Los signos ecográficos son inespecíficos y no permiten predecir el tipo histológico (Fig. 20). Las metástasis al testículo se diagnostican en pacientes mayores de 50 años $^{8,13}$.

\section{Infartos}

Una de las lesiones ecográficas nodulares que simulan un tumor es el infarto focal (Figs. 21 y 22). El infarto focal espontáneo es infrecuente, sin clínica, y muy difícil de diferenciar de una neoplasia. Algunos autores ${ }^{14}$ han señalado que habitualmente las neoplasias presentan abun- dante vascularización, y el Doppler color es útil en el diagnóstico diferencial con los infartos focales. Esto no ocurre siempre (Figs. 22 y 23). Son factores predisponentes para padecer infartos focales testiculares la policitemia, la anemia de células falciformes, la angeitis por hipersensibilidad, la displasia de la íntima en la arteria espermática y el traumatismo, aunque la mayoría de las veces son idiopáticos ${ }^{22,23}$.

Otras lesiones focales que simulan neoplasias son la orquitis, la fibrosis, abcesos, hematomas, lesiones secundarias a traumatismo o biosia por ejemplo para extracción de esperma, sarcoide, tuberculosis y tejido suprarrenal ectópico $^{8,24-27}$.

\section{Lesiones difusas de testículo}

Las lesiones testiculares que se manifiestan con este patrón son los linfomas, la leucemia,

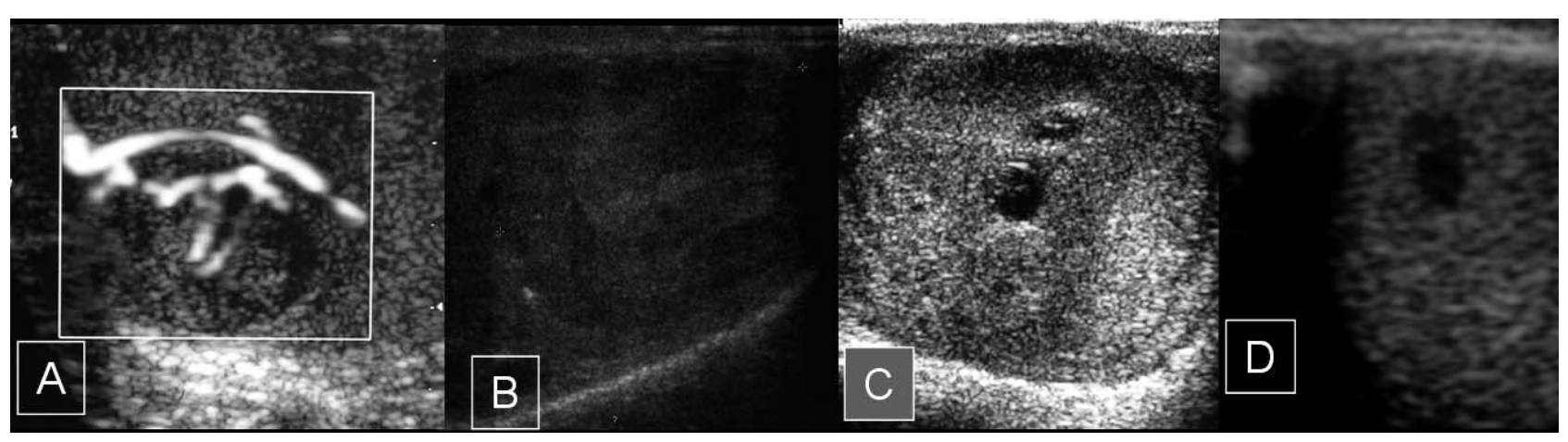

FIGURA 20. Diferentes tipos de neoplasias testiculares. Germinal mixto (A) nódulo sólido vascularizado, seminoma clásico de aspecto sólido (B) y complejo (C) y tumor de células de Leydig, lesión anecoica sin refuerzo simulando lesión quística (D).

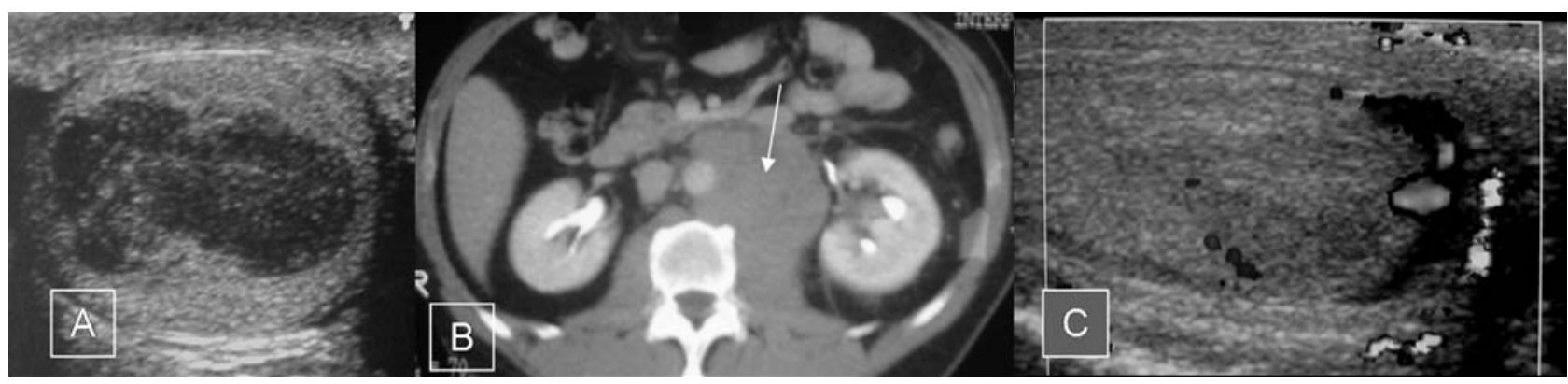

FIGURA 21. Lesión nodular en el testiculo (A) en un paciente joven con adenopatias retroperitoneales por Linfoma (flecha en B). Se repite la ecografía al ingresar en nuestro centro y se identifica un testiculo atrófico heterogéneo con escasa vascularización. Ante la sospecha de persistencia de enfermedad testicular por linfoma se decide hacer orquiectomia que demuestra infarto testicular. 


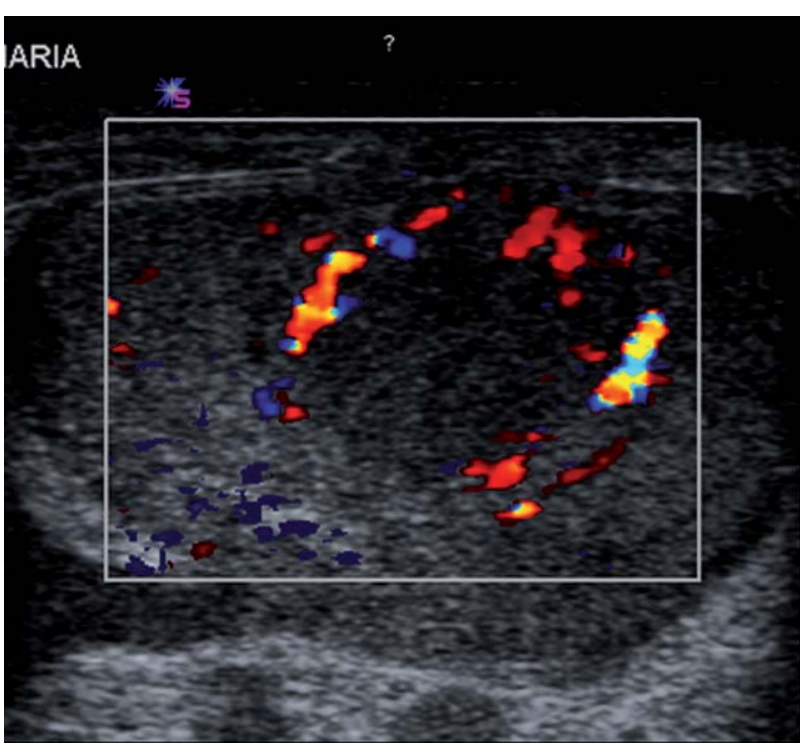

FIGURA 22. Infarto focal. Nódulo sólido hipoecoico escasamente vascularizado.

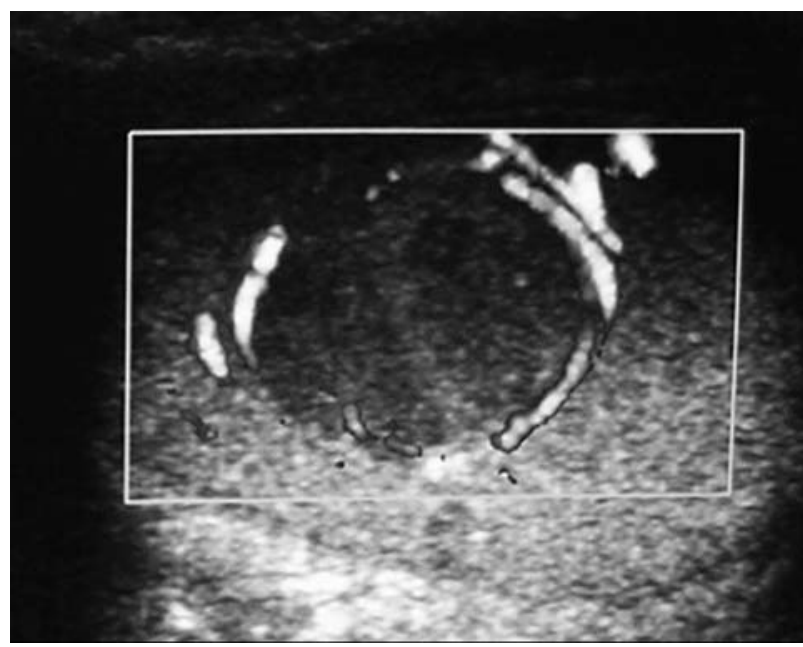

FIGURA 23. Carcinoma embrionario. Nódulo sólido hipoecoico escasamente vascularizado.

las orquitis, la sarcoidosis y la fibrosis. La afectación difusa puede manifestarse como un patrón difuso hipoecoico heterogéneo o estriado, en cebra, con bandas hiperecoicas e hipoecoicas alternativamente inespecífico (Figs. 24 y 25). Es rara esta presentación en las neoplasias germinales. La afectación por leucemia o linfoma del testículo constituye una indica-

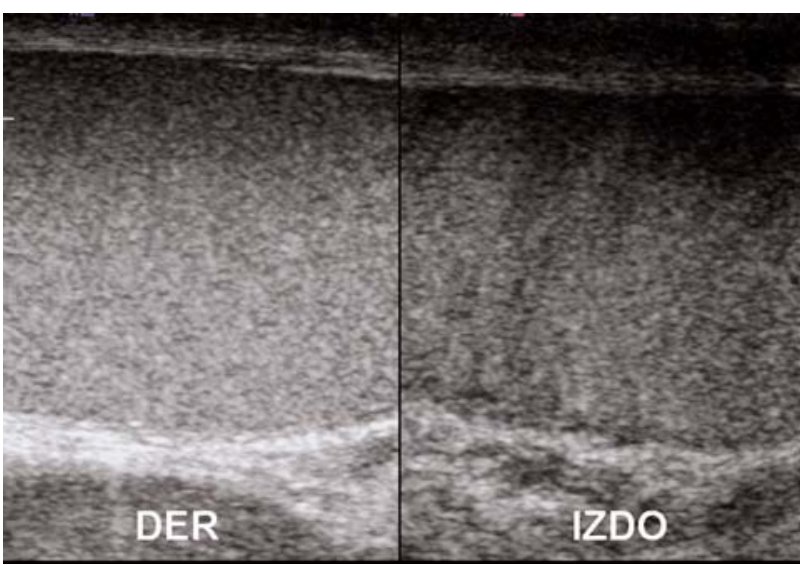

FIGURA 24. Orquitis izquierda 15 dias antes de la ecografia. Patrón hipoecoico difuso del teste izquierdo con aspecto estriado.

ción de orquiectomía. En estos pacientes la quimioterapia no atraviesa la barrera hematotesticular lo que explica la persistencia de enfermedad después de remisión. Por eso cualquier paciente con leucemia o linfoma y una masa testicular descubierta durante su enfermedad debe estudiarse mediante citologia e histología (Fig. 21). El linfoma es el tumor testicular más frecuente en mayores de 60 años. La afectación por linfoma puede ser secundaria a un linfoma B no Hodgkin, en la inmensa mayoría de los casos, o primaria. Los linfomas pueden también presentarse como nódulos múltiples testiculares. La bilateralidad $(8,5-$ $18 \%$ ) es más frecuente que en otro tipo de tumores testiculares. Los linfomas primarios de testículo, sin afectación ganglionar o sistémica son infrecuentes (Fig. 26) ${ }^{1,10,13,28,29}$.

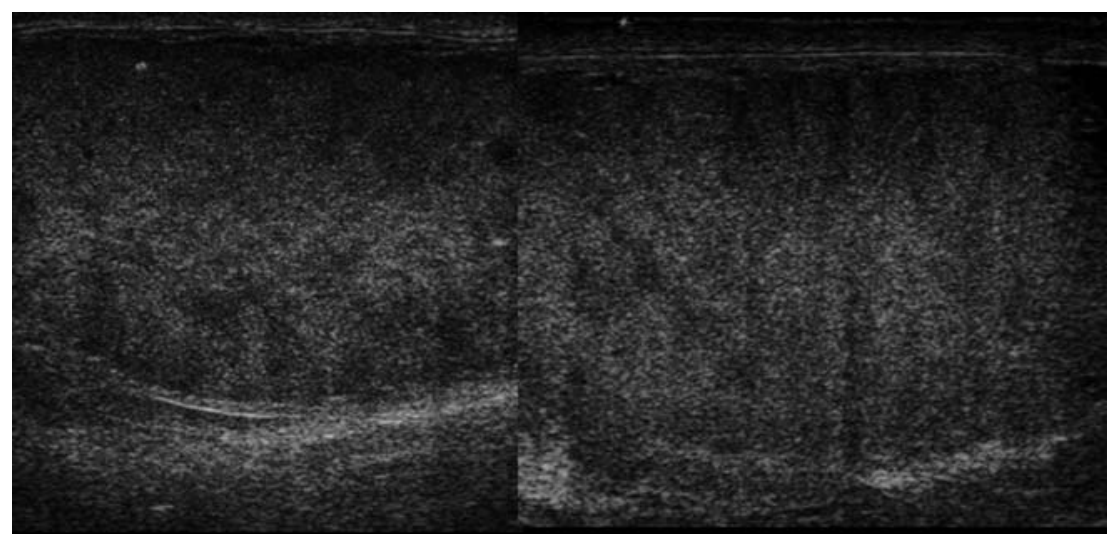

FIGURA 25. Paciente con linfoma y patrón hipoecoico estriado difuso bilateral. 


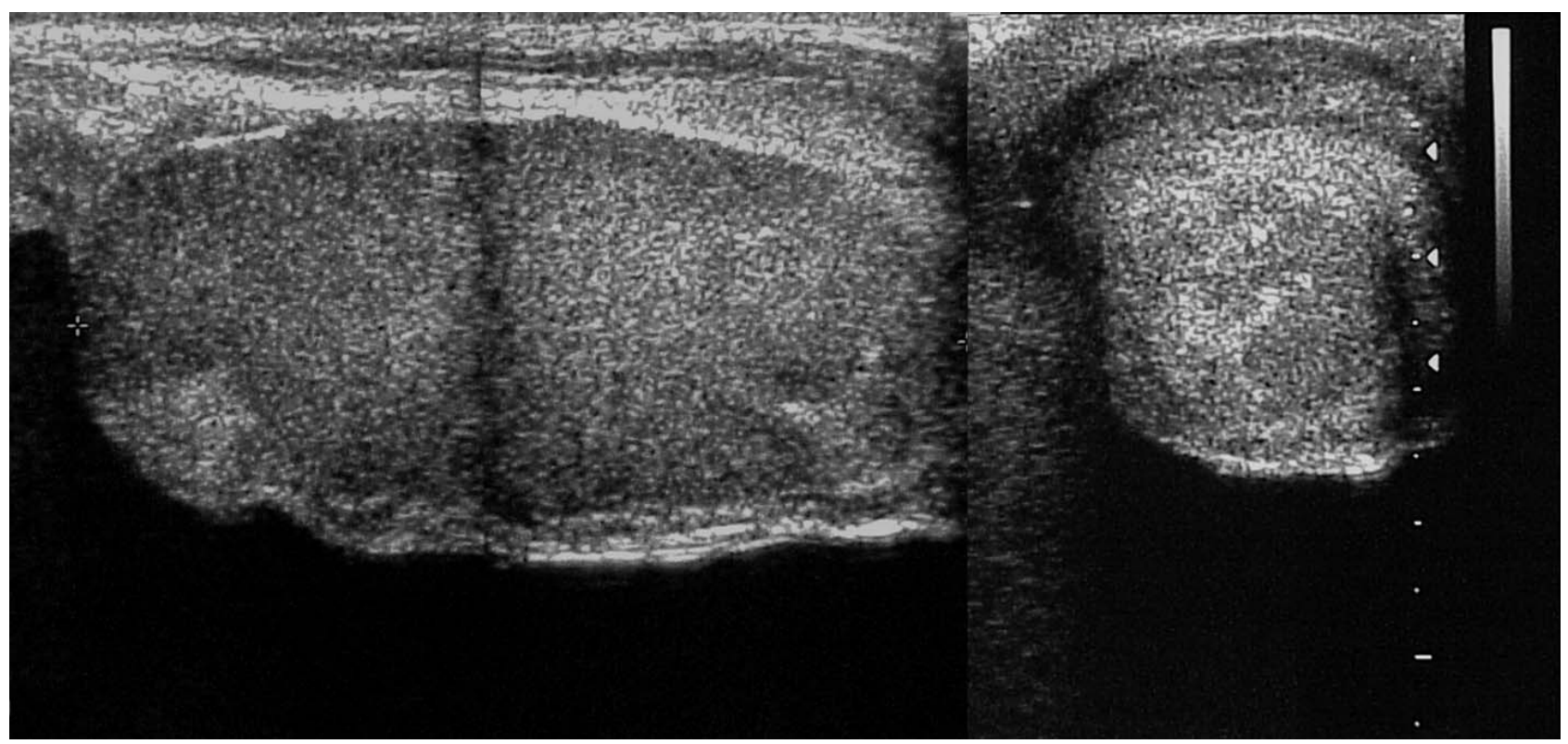

FIGURA 26. Linfoma no Hodgkin primario de testiculo Ecografia: Aumento de tamaño del teste -6cm- heterogéneo. Hidrocele. Aumento de tamaño del epididimo.

\section{Enfermedad extratesticular}

Otra de las utilidades de la ecografia escrotal es identificar hallazgos escrotales como marcadores de patología extraescrotal. Existe una importante relación entre los procesos que tienen lugar en el interior del escroto y los que ocurren fuera de él. Ya hemos comentado antes que en pacientes jóvenes adenopatías o lesiones metastásicas pueden ser explicadas por lesiones testiculares. También se ha señalado que un varicocele derecho es un marcador de patología extraescrotal. En un paciente joven con masas retroperitoneales, mediastínicas o metástasis de origen desco- nocido está indicado realizar una ecografía testicular (Figs. 21 y 27). El varicocele derecho per se obliga a descartar patología retroperitoneal (Fig. 28) o situs inversus ${ }^{8}$.

\section{"Burn out tumor"}

Es una entidad extremadamente rara, en la que en la mayoría de los casos la ecografia escrotal permite explicar lesiones extraescrotales. Consiste en metástasis de tumor de células germinales sin evidencia de neoplasia gonadal o con neoplasia intratubular. Representa una regresión espontánea y completa de un tumor testicular.

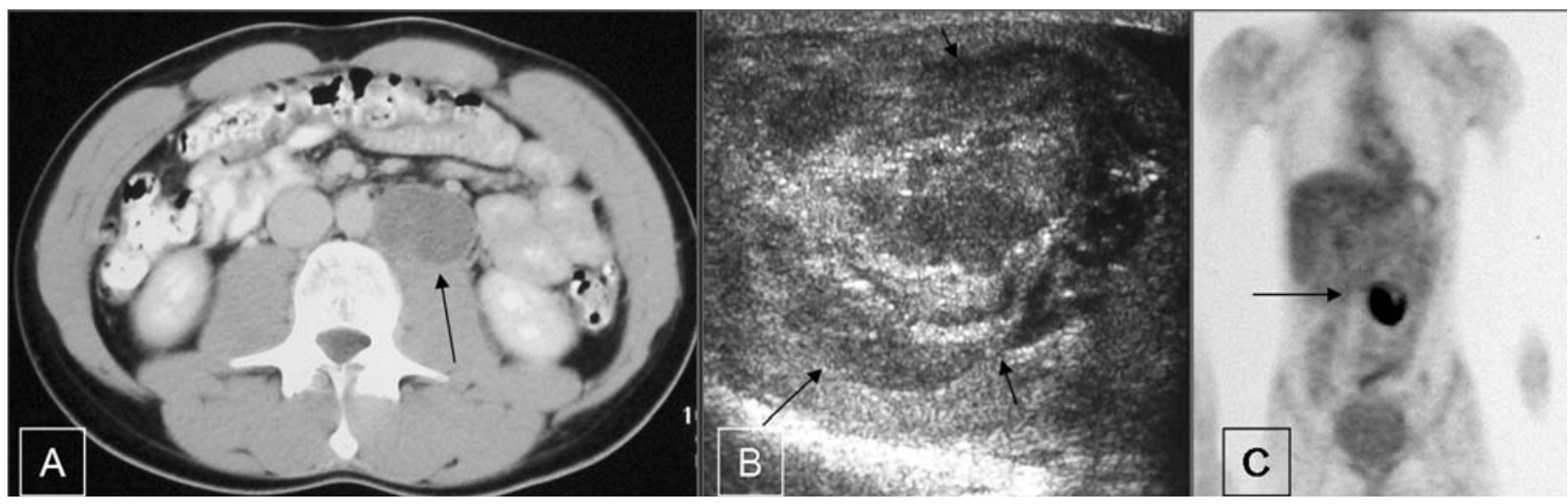

FIGURA 27. Paciente de 20 años con adenopatias retroperitoneales demostradas en TC (flecha en A). La ecografia testicular demuestra una masa sólida heterogénea (B, flecha). La estadificación se completó con un PET que no demostró más captación que dichas adenopatias (flecha en $\mathrm{C}$ ). La orquiectomía demostró un tumor mixto de células germinales. 


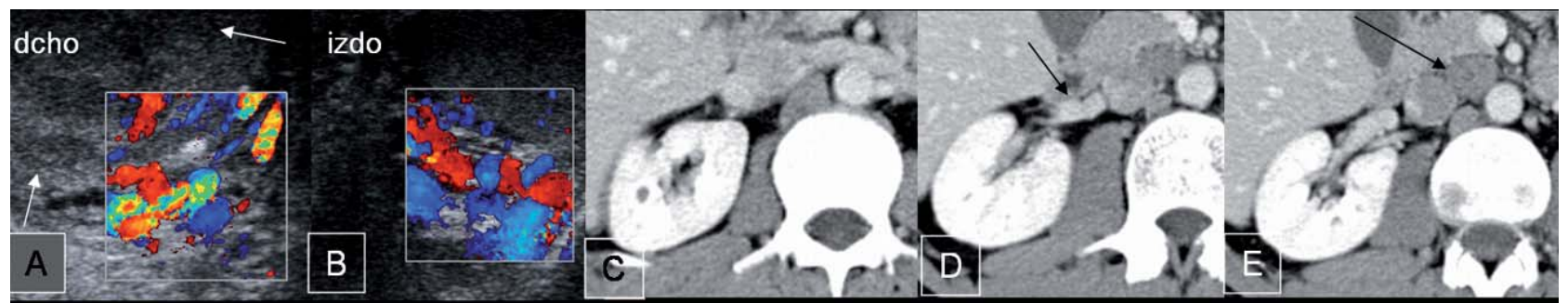

FIGURA 28. Varicocele bilateral (A y B) y nódulo testicular derecho (flechas en A). Se realiza estudio mediante TC y se identifica adenopatia retroperitoneal derecha (flecha en E) que dificulta el drenaje de la vena espermática a la vena renal derecha (flecha en $D)$.

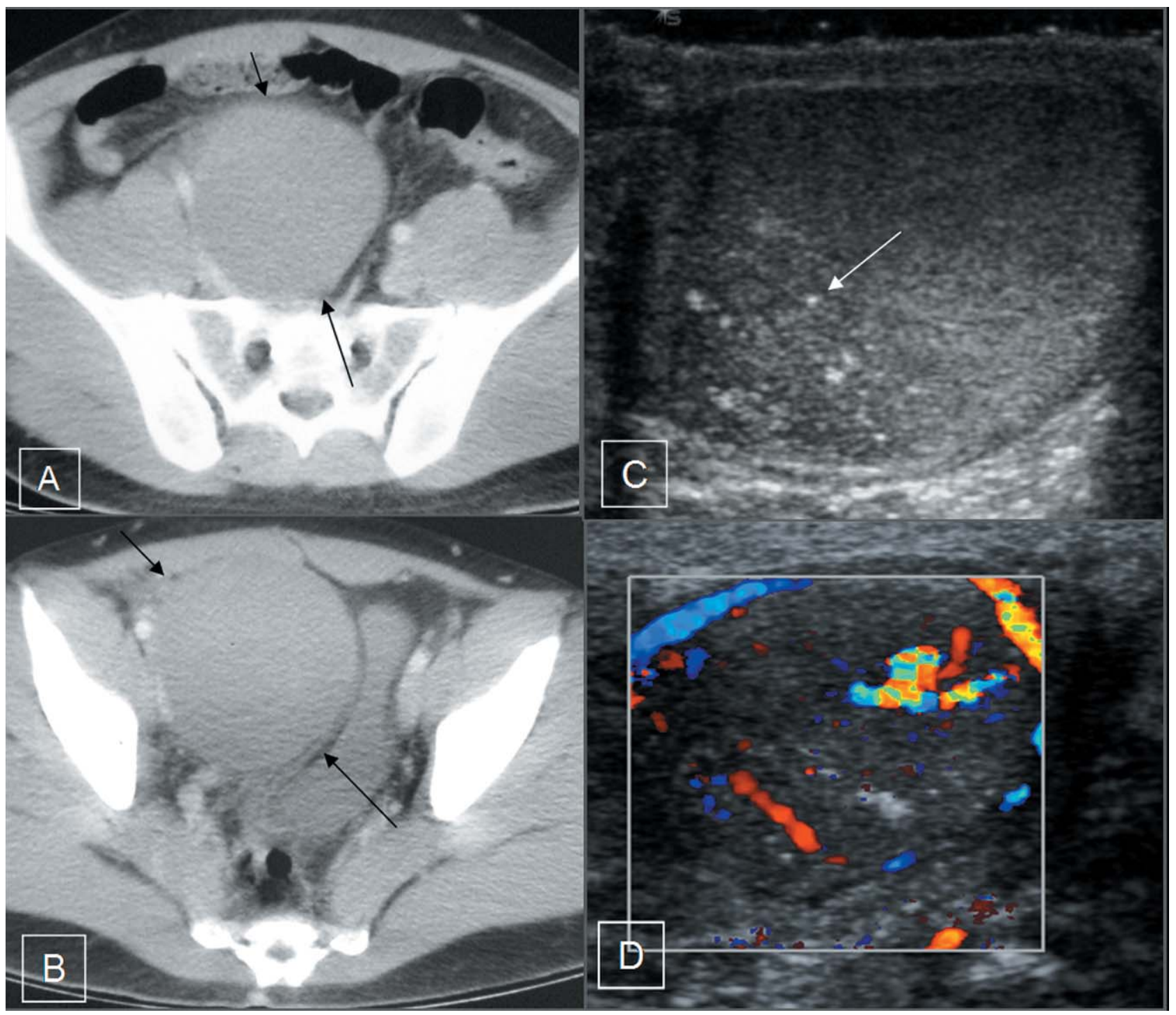

FIGURA 29. Paciente de 28 años con masa pélvica en CT (flechas en $\mathrm{A}$ y B) que desplaza inferiormente la vejiga (histología de la masa: seminoma clásico). Aspecto heterogéneo hipoecóico del teste derecho con calcificaciones pequeñas en US (flecha en C), sin nódulos. Histología del teste derecho: Lesión cicatricial. Neoplasia intratubular de cels germinales. Microcalcificaciones (psamoma). El teste izquierdo con alguna microcalcificación (D), atrófico y sin alteración en Doppler no se opera a petición del paciente. Se realiza ecografia testicular periódica y continúa en revisión sin evidencia de enfermedad. 


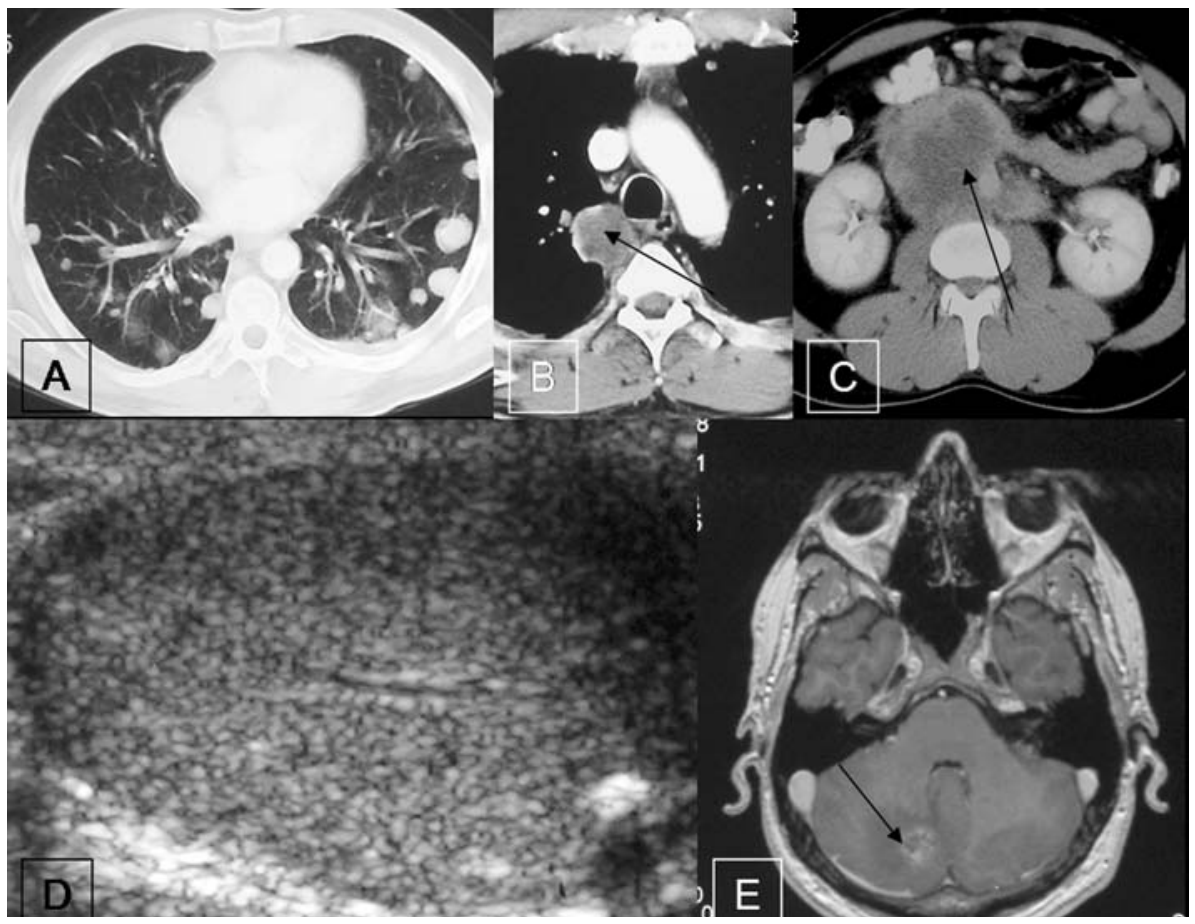

FIGURA 30. Paciente de 33 años que consulta por dolor abdominal. Se realiza radiografia de tórax que demuestra una masa mediastínica. En el TC torácico y abdominal se identifica metástasis pulmonares (A), adenopatias mediastinicas (flecha en B) y retroperitoneales (flecha en C). Se biopsia un ganglio supraclavicular con resultado de metástasis de un tumor germinal maligno (coriocarcinoma). Ecografia testicular (D) sin evidencia de nódulos con una calcificación grosera y aspecto algo heterogéneo. El paciene presentaba simultáneamente metástasis cerebelosas (RM: áreas hipointensas y captación en anillo: flecha en E). Histologia teste: Neoplasia intratubular de células germinales. Cicatriz fibrosa compatible con regresión completa de un tumor primario. Hiperplasia de células de Leydig.

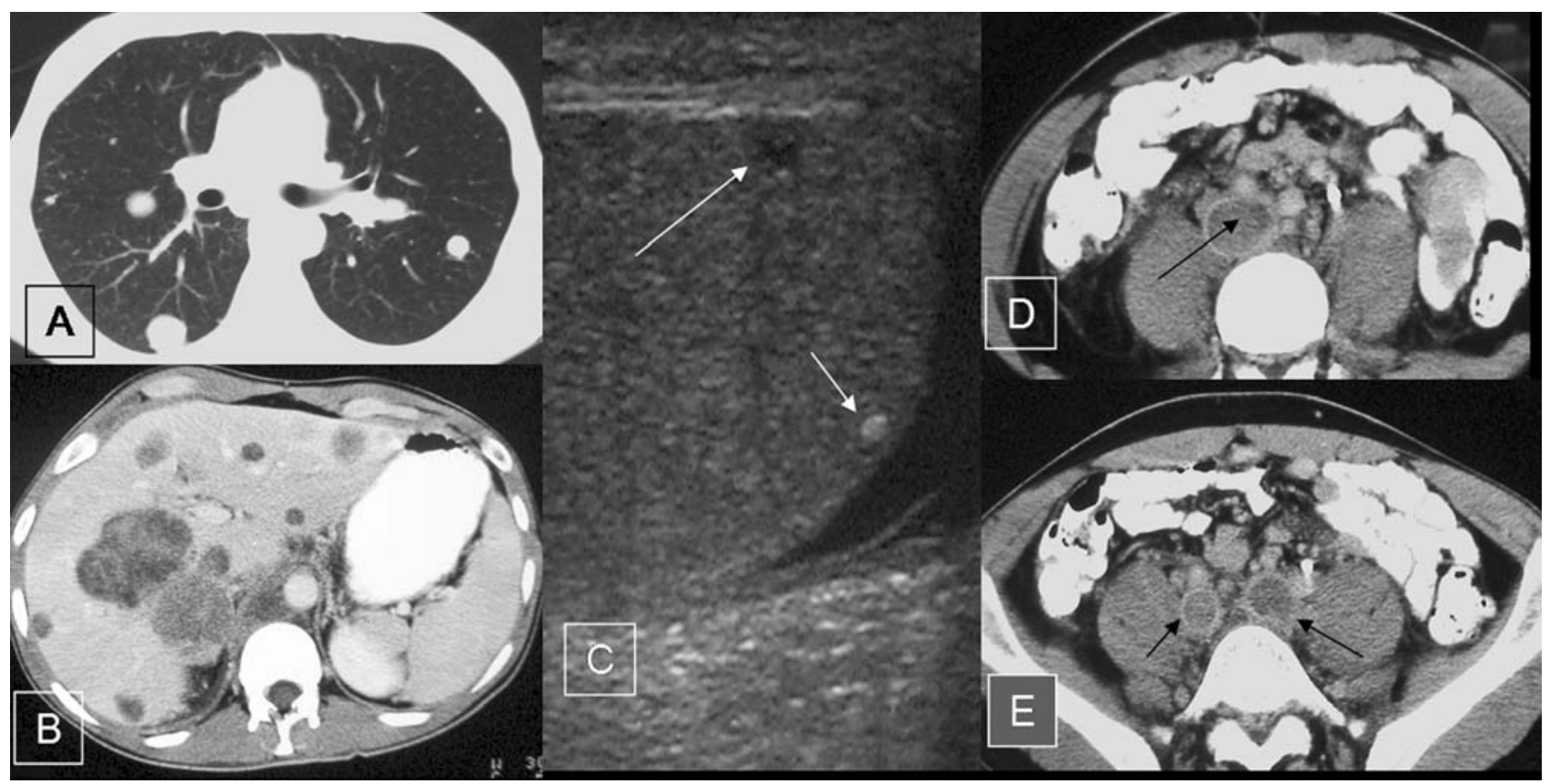

FIGURA 31. Paciente de 26 años con dolor lumbar de 3 meses de evolución. En el TC se identificaron masas retroperitoneales que engloban el riñón (no mostradas), metástasis pulmonares (A) y hepáticas (B). Trombosis de cava inferior y sus ramas (flechas en $D$ y E). Ante la sospecha de neoplasia testicular o linfoma se realiza US que no demuestra nódulos. Se identifica un quiste periférico de $3 \mathrm{~mm}$ (flecha larga en C) y una calcificación aislada (flecha corta en C). Se realiza PAAF guiada por TC de la masa retroperitoneal (Citología maligna, compatible con metástasis de un carcinoma embrionario, de probable origen testicular). El resultado de la orquiectomía: Quiste de inclusión epidérmico. Testículo ligeramente atrófico.

Existen anormalidades en la ecografia testicular de todos los casos publicados (calcio, cicatrices, áreas hipoecóicas) (Figs. 29 -31) ${ }^{30,31}$. La histolo- gía testicular es anormal en un $76 \%$ (hialinosis, fibrosis, depósitos de hemosiderina, neoplasia intratubular). 


\section{CONCLUSIONES}

El conocimiento de la anatomía normal ecográfica, de los diferentes patrones de presentación de las lesiones y de los hallazgos escrotales que indican patología extratesticular ayudan en el manejo de los pacientes y pueden evitar cirugias innecesarias.

\section{REFERENCIAS}

1. Dogra VS, Gottlieb RH, Oka M, Rubens DJ. Sonography of the scrotum. Radiology. 2003 Apr;227(1):18-36. Epub 2003 Feb 28.

2. Rouviere O, Bouvier R, Pangaud C, Jeune C, Dawahra M, Lyonnet D. Tubular ectasia of the rete testis: a potential pitfall in scrotal imaging. Eur Radiol. 1999;9(9):1862-1868.

3. Dogra VS, Gottlieb RH, Rubens DJ, Liao L. Benign intratesticular cystic lesions: US features. Radiographics. 2001 Oct;21 Spec No:S273-281.

4. Sellars ME, Sidhu PS. Ultrasound appearances of the testicular appendages: pictorial review. Eur Radiol. 2003 Jan; 13(1):127-35. Epub 2002 Apr 3.

5. Baldisserotto M, de Souza JC, Pertence AP, Dora MD. Color Doppler sonography of normal and torsed testicular appendages in children. AJR Am J Roentgenol. 2005 Apr; 184(4): 1287-92.

6. Dogra V, Bhatt S. Acute painful scrotum. Radiol Clin North Am. 2004 Mar;42(2):349-363.

7. Sarrat R. Anatomía del aparato urogenital. En: Tratado de Urología Dres. Jiménez Cruz y Rioja Sanz. Tomo I. Prous Editores. Barcelona 1993. p: 17-40.

8. Middleton WD, Kurtz AB, Hertzberg BS. Ecografia. Marban, 2005. Madrid.

9. Ruiz Liso JM, Ruiz García J, del Agua Arias C, Vaillo Vinagre A, Gutiérrez Martín A, García Pérez MA. Proliferación nodular y difusa fibrosa de la túnica vaginal del testículo. Presentación de un nuevo caso y revisión de la literatura. Rev Esp Patol 2004;Vol 37,1:91-98.

10. Woodward PJ, Schwab CM, Sesterhenn IA. Extratesticular Scrotal Masses: Radiologic-Pathologic Correlation. Radiographics. 2003 Jan-Feb;23(1):215-240

11. Linkowski GD, Avellone A, Gooding GA. Scrotal calculi: sonographic detection. Radiology. 1985 Aug;156(2):484.

12. Bushby LH, Miller FN, Rosairo S, Clarke JL, Sidhu PS. Scrotal calcification: ultrasound appearances, distribution and aetiology. Br J Radiol. 2002 Mar;75(891):283-288.

13. Muttarak M, Chaiwun B. Painless scrotal swelling: ultrasonographical features with pathological correlation. Singapore Med J. 2005 Apr;46(4):196-201; quiz 202.

14. Dogra VS, Gottlieb RH, Oka M, Rubens DJ. Sonography of the scrotum. Radiology. 2003 Apr;227(1):18-36. Epub 2003 Feb 28

15. Kocao?lu M, Bozlar U, Bulakba?ı N, Sa?lam M, Üçöz T, Somuncu I. Testicular microlithiasis in pediatric age group: ultrasonography findings and literature review. Diagn Interv Radiol 2005 11:60-65.

16. Kim B, Winter TC, Ryu J. Testicular microlithiasis: clinical significance and review of the literature. Eur Radiol. 2003 Dec; 13(12):2567-2576. Epub 2003 Oct 3.
17. Maizlin ZV, Belenky A, Baniel J, Gottlieb P, Sandbank J, Strauss S. Epidermoid cyst and teratoma of the testis: sonographic and histologic similarities. J Ultrasound Med. 2005 Oct;24(10):1403-9; quiz 1410-1411.

18. Cho JH, Chang JC, Park BH, Lee JG, Son CH. Sonographic and MR imaging findings of testicular epidermoid cysts. AJR Am J Roentgenol. 2002 Mar; 178(3):743-748.

19. Browne RF, Geoghegan T, Ahmed I, Torreggiani WC. Intratesticular varicocele. Australas Radiol. 2005 Aug;49(4): 333-334.

20. Atasoy C, Fitoz S. Gray-scale and color Doppler sonographic findings in intratesticular varicocele. J Clin Ultrasound. 2001 Sep;29(7):369-373.

21. Shergill IS, Thwaini A, Kapasi F, Potluri BS, Barber C. Management of simple intratesticular cysts: a single-institution 11-year experience. Urology. 2006 Jun;67(6):12661268.

22. Flanagan JJ, Fowler RC. Testicular infarction mimicking tumour on scrotal ultrasound-a potential pitfall. Clin Radiol. 1995 Jan;50(1):49-50.

23. Sriprasad S, Kooiman GG, Muir GH, Sidhu PS. Acute segmental testicular infarction: differentiation from tumour using high frequency colour Doppler ultrasound. $\mathrm{Br} \mathrm{J}$ Radiol. 2001 Oct;74(886):965-967.

24. Strauss S, Belenky A, Cohen M, Manor H, Avrech OM, Fisch B, Ron-El R. Focal testicular lesion after sperm extraction or aspiration: sonographic appearance simulating testicular tumor. AJR Am J Roentgenol. 2001 Jan; 176(1):113-115.

25. Einstein DM, Paushter DM, Singer AA, Thomas AJ, Levin HS. Fibrotic lesions of the testicle: sonographic patterns mimicking malignancy. Urol Radiol. 1992;14(3):205-210.

26. Barwick TD, Malhotra A, Webb JA, Savage MO, Reznek RH. Embryology of the adrenal glands and its relevance to diagnostic imaging. Clin Radiol. 2005 Sep;60(9):953-939.

27. Salmeron I, Ramirez-Escobar MA, Puertas F, Marcos R, Garcia-Marcos F, Sanchez R. Granulomatous epididymoorchitis: sonographic features and clinical outcome in brucellosis, tuberculosis and idiopathic granulomatous epididymo-orchitis. J Urol. 1998 Jun;159(6):1954-1957.

28. Wallace DJ, Altemare CR, Shen de F, deSmet MD, Buggage RR, Nussenblatt RB, Chan CC. Primary testicular and intraocular lymphomas: two case reports and a review of the literature. Surv Ophthalmol. 2006 Jan-Feb;51(1):41-50.

29. Mazzu D, Jeffrey RB, Ralls PW. Lymphoma and leukemia involving the testicles: findings on gray-scale and color Doppler sonography. AJR Am J Roentgenol. 1995 Mar; 164(3):645-647.

30. Sesterhenn IA, Davis CJ. Pathology of germ cell tumors of the testis. Cancer Control. 2004 Nov-Dec;11(6):374-387.

31. Perimenis P, Athanasopoulos A, Geraghty J, Macdonagh R. Retroperitoneal seminoma with 'burned out'phenomenon in the testis. Int J Urol. 2005 Jan;12(1):115-116.

Correspondencia autora: Dra. E. de Luis Pastor

Servicio de Radiología. Clínica Universitaria de Navarra

Avda. Pío XII, 36 - 31008 Pamplona (Navarra). Tel.: 948255400

E-mail autora: edeluis@unav.es

Información artículo: Original - Urología general

Trabajo recibido: junio 2007

Trabajo aceptado: julio 2007 